\title{
The adverse effects of systematic leakage ahead of official sovereign debt rating announcements
}

\author{
Alexander Michaelides $^{\mathrm{a}, \mathrm{b}, \mathrm{c}, *}$, Andreas Milidonis $^{\mathrm{b}, \mathrm{d}, 1}$, George P. Nishiotis ${ }^{\mathrm{b}, 2}$, \\ Panayiotis Papakyriakou ${ }^{\mathrm{b}, 3}$ \\ a Department of Finance, Imperial College Business School, South Kensington Campus, London SW72AZ, UK \\ ${ }^{\mathrm{b}}$ Department of Accounting E' Finance, School of Economics \&' Management, University of Cyprus, P.O. Box 20537, CY-1678 Nicosia, Cyprus \\ ${ }^{\mathrm{c}}$ Centre for Economic Policy Research, 77 Bastwick Street, London EC1V 3PZ, UK \\ ${ }^{\mathrm{d}}$ Nanyang Technological University, Singapore
}

\section{A R T I C L E I N F O}

\section{Article history:}

Received 28 December 2012

Received in revised form

30 July 2014

Accepted 26 August 2014

Available online 8 January 2015

\section{JEL classification:}

G14

G15

G18

G24

Keywords:

Sovereign ratings

Event studies

Institutional quality

Information leakage

TRMI

\begin{abstract}
A B S T R A C T
Rating agencies consult with local government officials several days prior to official announcements of sovereign debt rating changes, making information leakage likely. Using cross-country data from 1988 to 2012, we find evidence of information leakage. In particular, we find statistically and economically significant negative daily abnormal stock index returns prior to downgrade announcements. These effects are more pronounced in countries with lower institutional quality, and they persist during times with no downgrade rumors and no concurrent bad news in general. A mild post-announcement reversal consistent with overreaction to pre-event downgrade rumors highlights the adverse effects of such leakage and, thus, should be a policy concern for capital market regulators.
\end{abstract} (c) 2015 Published by Elsevier B.V.

\footnotetext{
This paper has been previously circulated under the title "Sovereign debt rating changes, institutional quality and the stock market". We thank the University of Cyprus and the Insurance Risk and Finance Research Centre (IRFRC) at Nanyang Business School for a research grant. We also thank an anonymous referee, George Constantinides, Zhi Da, Bernardo Guimaraes, Peter Hoffmann (discussant), Ravi Jagannathan, Robert Korajczyk, David Lesmond, Nadia Massoud, Marco Pagano, Marios Panayides, Roger Stein (discussant), Lenos Trigeorgis, Avi Wohl and participants at seminars and conferences at the following institutions for their comments: Imperial College, Manchester Business School, National University of Singapore, Pontifical Catholic University of Chile, University of St. Gallen; C.R.E.D.I.T. (Credit Risk Evaluation Designed for Institutional Targeting in finance), EFMA (European Financial Management Association), SED (Society for Economic Dynamics) and WU Gutmann Center for Portfolio Management. We would also like to thank Thomson Reuters for providing Thomson Reuters Marketpsych Indices (TRMI) for our analysis.

* Corresponding author at: Department of Finance, Imperial College Business School, South Kensington Campus, London SW72AZ, UK. Tel.: +442075949177.

E-mail addresses: a.michaelides@imperial.ac.uk (A. Michaelides), andreas.milidonis@ucy.ac.cy (A. Milidonis), nishiotis.george@ucy.ac.cy (G.P. Nishiotis), papakyriacou.panayiotis@ucy.ac.cy (P. Papakyriakou).

1 Tel.: + 35722893626

2 Tel.: + 35722893617 .

3 Tel.: + 35722893605 .
} 


\section{Introduction}

When sovereign ratings are being revised, credit rating agencies consult with the rated entity after the rating decision has been approved but before the public announcement. This consultation period can last several days, jeopardizing the confidentiality of information related to the forthcoming, unscheduled sovereign debt rating change. Therefore, it could be associated with economically significant, destabilizing effects for local stock markets.

As an example, consider events around the August 2011 downgrade of Cypriot sovereign government debt by Fitch. On Thursday, August 4, 2011 the Cypriot stock market fell by $3.6 \%$, and the next trading day it fell an additional $4.1 \%$. On Saturday, August 6, the head of the Cyprus Securities and Exchange Commission made a public plea that anyone having information that should be in the public domain immediately disclose it. The following trading day (Monday, August 8) coincided with a public holiday in London, England (Fitch covers Cyprus out of its London office), and the market fell another 5.69\%. Fitch downgraded Cypriot sovereign debt by two notches on Wednesday, August 10, after which the local market rose by $0.6 \%$ (it remained unchanged on August 9). Fig. 1 shows the economically significant cumulative drop in the Cypriot stock market index, reaching around $30 \%$ in the ten days before the announcement. One interpretation of these events is that the imminent downgrade was leaked during the consultation process between the credit rating agency (CRA) and local authorities before the public announcement. ${ }^{4}$

In this paper, we examine whether the case of Cyprus, which is suggestive of information leakage, is an isolated incident or whether it is representative of international experience ahead of official announcements of sovereign debt rating changes. To do so, we collect daily local stock market index return data for every rated country from the three largest CRAs [Fitch, Moody's, and Standard and Poor's (S\&P)] between 1988 and 2012, resulting in a sample of four hundred upgrades and 291 downgrades from 65 countries. $^{5}$

\footnotetext{
${ }^{4}$ As an example from a more developed market, consider the US government debt rating downgrade by Standard and Poor's (S\&P) in August 2011. The ten-day cumulative decline in raw daily returns for the S\&P 500 reached $11 \%$ before the announcement. Anecdotal evidence in the press (Wall Street Journal, 2011) suggests that information about the imminent downgrade leaked to the market ahead of the actual announcement. The US Securities and Exchange Commission (SEC) launched an investigation into the potential leakage of information, and in its September 30, 2011 summary report (SEC, 2011) identified a number of concerns, which "included apparent failures in some instances to follow ratings methodologies and procedures, to make timely and accurate disclosures, to establish effective internal control structures for the rating process and to adequately manage conflicts of interest." If rating announcements in the highly regulated and monitored capital market of the US are associated with such concerns, then rating announcements in less regulated and monitored capital markets can be expected to generate even more concerns.

5 To mitigate the problem arising from simultaneous rating actions across agencies, our primary definition of an event is based on the CRA that moves first in making a public announcement.
}

We find statistically and economically significant changes in local stock market returns around official announcements of sovereign debt rating downgrades. ${ }^{6}$ The cumulative abnormal stock index return over event window $[-5,-3]$ is $-0.806 \%$, and that over event window $[0,1]$ is $-0.57 \%$. The negative abnormal returns appear to be partially reversed in the post-announcement period. The net effect over the $[-5,+5]$ window is $-0.631 \%$, which includes a statistically significant reversal after the event. $^{7}$

What could explain the pre-announcement stock market declines? One possibility is that information leaks to the market before a CRA's official announcement. When CRAs decide to revise a country's sovereign debt rating, several days before making the official (public) announcement they communicate their intention to officials of the rated country for feedback. During this consultation period, information is shared between the two parties and, thus, information can be leaked by the CRA or by local government officials (IOSCO, 2004). ${ }^{8}$ Under the information leakage hypothesis, stronger leakage effects would be expected in countries with lower quality institutions. Using a widely accepted measure of transparency, the Corruption Perception Index from Transparency International (TI), we find that our results are driven by lower transparency countries, consistent with the information leakage hypothesis. ${ }^{9}$

The above analysis is subject to endogeneity concerns. Stock markets in countries with large pre-event abnormal returns (implying high insider trading) are more likely to be classified as low institutional quality (see, for example, Khwaja and Mian, 2005). That is, institutional quality could depend on abnormal stock return reactions to public announcements instead of the reverse. To address endogeneity concerns, we employ instrumental variables for institutional quality identified by prior literature (La Porta, Lopez-de-Silanes, Shleifer, and Vishny, 1998; Alesina, Devleeschauwer, Easterly, Kurlat, and Wacziarg, 2003; and Easterly and Levine, 2003) that pass weak instrumental variable tests. The coefficients in the two-stage least squares (TSLS) regressions remain economically and statistically significant. A 1 standard deviation decrease in the

\footnotetext{
${ }^{6}$ The economic significance of the market reaction to downgrades appears to be stronger than the market reaction to upgrades, consistent with findings in the corporate bond ratings literature (for example, see Milidonis, 2013; Berwart, Guidolin and Milidonis, 2014; and references therein).

7 Similarly, the cumulative abnormal return over the $[-10,-3]$ window is $-1.64 \%$, and that over the $[-10,+10]$ window including the reversal is $-1.21 \%$, both statistically significant.

${ }^{8}$ In July 2011 (January 2012) Italian prosecutors raided Moody's (Fitch) offices, accusing the CRA of leaking information about the sovereign debt downgrades before the public announcement (Rossi, 2012). Even in well-regulated markets such as the US, the idea of soft corruption (by government officials) is prevalent in the press as illustrated by the November 201160 Minutes “Insiders" report on CBS (Kroft, 2012).

${ }^{9}$ The negative pre-event local stock market reaction continues to hold when we use other measures of institutional quality, such as a country's legal origin (common versus civil law), World Bank development classification (emerging and frontier versus developed), and law and order score (published by the Political Risk Services Group).
} 


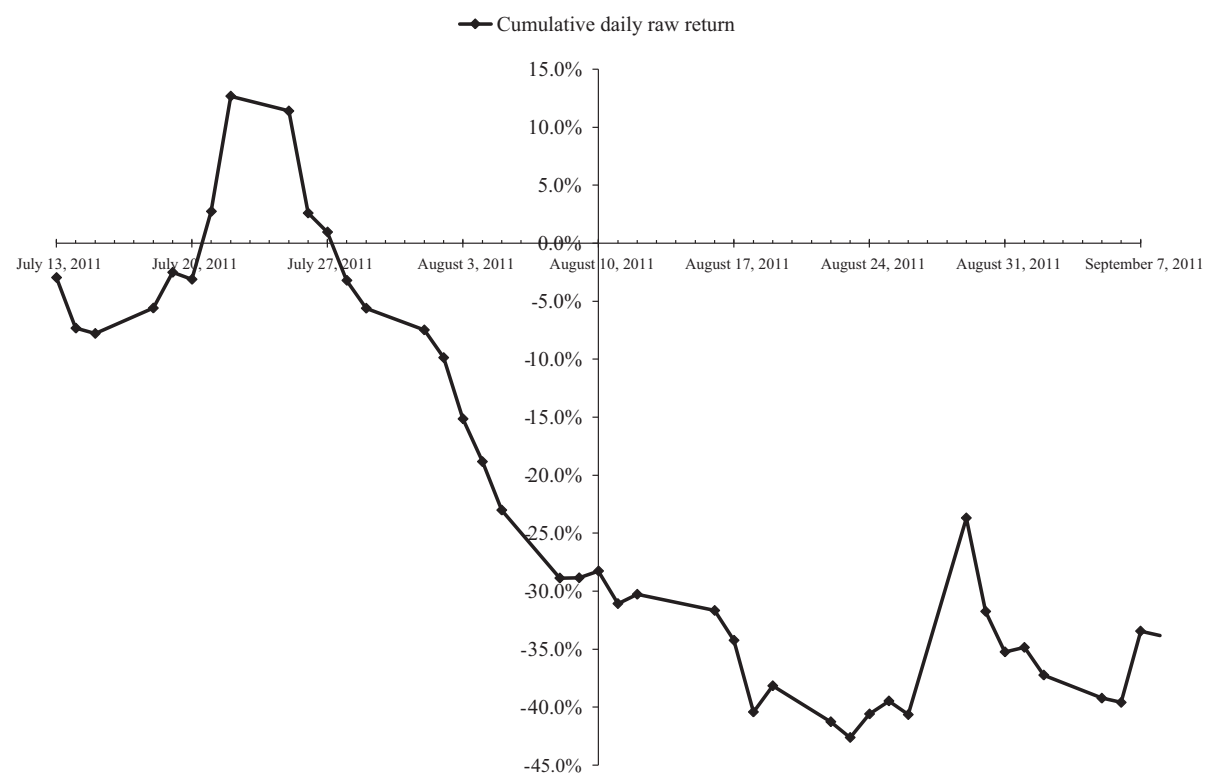

Fig. 1. Cyprus stock index (raw returns) around the August 2011 sovereign debt downgrade. Depicted are cumulative raw returns in the 20 days before and after the sovereign debt rating downgrade of Cyprus by Fitch on August 10, 2011.

transparency score leads to a $1.25 \%$ more negative cumulative abnormal return over the window $[-5,-3]$. This evidence points to a causal relation between institutional quality and pre-announcement stock market declines and, thus, provides further support for the information leakage hypothesis.

An alternative explanation for pre-announcement stock market declines could be the presence of bad news unrelated to a forthcoming sovereign downgrade in the pre-event window. We take the view that news related to a forthcoming downgrade (i.e., a rumor) is associated with information leakage and that news unrelated to the possibility of a downgrade is not. To construct our news variables, we first use LexisNexis to identify news stories with references to a downgrade in the ten-day window before the announcement (i.e., rumors). About $40 \%$ of downgrade announcements have at least one relevant news item preceding them, thus providing initial evidence that information leakage is taking place. We then complement the manual news search using proxies for the frequency and content (i.e., sentiment) of news recently developed by Thomson Reuters MarketPsych Indices (TRMI). The TRMI measures capture all country-specific news, both related and unrelated to a sovereign downgrade, on a daily basis. Confirming the validity of the news-related measures, we find no abnormal negative sentiment when downgrades are not preceded by rumors, while we find abnormal negative sentiment when downgrades are preceded by rumors. Given that negative abnormal stock market reactions before an announcement persist when there are no rumors in the news and when there is no concurrent unrelated bad news (abnormal reaction to TRMI variables), we conclude that these reactions are due to leakages not observed in the news.

The systematic leakage of information ahead of sovereign debt downgrade announcements appears to be destabilizing for local stock markets, as we find a partial post-announcement reversal. The post-event reversal reduces the overall announcement effect, consistent with a correction of a pre-event overreaction to rumors related to the downgrades. ${ }^{10}$ The destabilizing stock market effects of systematic leakage during the consultation process between CRAs and local government officials ahead of official sovereign debt rating announcements should be a source of concern for capital market regulators.

In an effort to mitigate such effects, in June 2013 the European Union passed a law (EU, 2013) requiring that official announcements of sovereign rating changes be scheduled events. Since then, sovereign debt rating announcements are prescheduled on Fridays after the close of business. Interestingly, for 2014, the three CRAs have posted on their websites scheduled announcements for European and non-European sovereign entities they rate. However, the new law states that CRAs should give rated entities at least 24 hours' notice when the sovereign rating is being revised and an announcement is imminent. To better safeguard the confidentiality of information related to rating actions, the simplest solution could be to dispense with the pre-announcement consultation process altogether, as markets can evaluate the information value inherent in scheduled announcements. Should the consultation process remain, an upper bound on the communication window between the CRA and local government officials could be specified (e.g., no more than 48 hours prior to the announcement) to decrease the likelihood of information leakage.

\footnotetext{
${ }^{10}$ This result is in line with the theoretical framework of leakage and insider trading of Brunnermeier (2005).
} 
The literature on the effects of sovereign debt downgrades on stock markets is relatively recent. Our result that leakage is more likely in lower institutional quality countries echoes findings of price manipulation in an emerging stock market (Khwaja and Mian, 2005). Brooks, Faff, Hillier, and Hillier (2004) also find a negative effect of rating downgrades on stock returns, but we differ by providing evidence of information leakage before the official announcement, especially in countries with lower institutional quality. Martell (2005) and Hill and Faff (2010) further find evidence of movements in stock returns before rating announcements, but we differ from these papers by showing a causal link between sovereign institutional quality and stock market reactions prior to downgrades and by conducting an extensive analysis of preannouncement news to show that our results are driven not by concurrent news unrelated to the downgrade, but rather by the leakage of information.

Afonso, Furceri and Gomes (2012) focus on sovereign bond yield responses to rating changes in EU countries and find evidence of bi-directional causality between yields and rating changes, consistent with event anticipation. Our results emphasize a large decline in the stock market before an official announcement in countries with weaker institutions, a finding that is hard to reconcile with event anticipation in such countries. Building on Kaminsky and Schmukler (2002), Gande and Parsley (2005) find evidence of contagion in government bond yields across countries following sovereign debt downgrades. The TRMI measures can identify instances in which one would expect spillovers from one country to another. We find negative preannouncement abnormal stock returns even in subsamples without any sovereign downgrade news ahead of the downgrade or abnormal changes in TRMIs before the announcement. In addition, while contagion is more likely to appear in crisis periods, our results are qualitatively similar in crisis periods (e.g., the Asian, Russian and European, sovereign debt crises) and non-crisis periods, thus providing further evidence in support of the leakage hypothesis.

The remainder of the paper is organized as follows. In Section 2, we discuss the institutional background and develop our hypotheses. In Section 3, we discuss our data and provide descriptive statistics. Event study results are reported in Section 4. We test the leakage hypothesis in Section 5 and the alternative hypothesis of concurrent unrelated bad news in Section 6. Section 7 considers policy implications, and Section 8 concludes.

\section{Institutional background and hypothesis development}

The International Organization of Securities Commissions (IOSCO) sets global standards for securities markets. Together with more than 120 securities regulators as well as the G20 and the Financial Stability Board (FSB), IOSCO develops and encourages adoption of regulations consistent with international securities standards. Its combined mandate covers over 95\% of the world's markets.

To the best of our knowledge, IOSCO first issued (nonobligatory) guidance on the process CRAs should follow in publicly announcing sovereign rating actions in 2004. The
IOSCO "Code of Conduct Fundamentals for Credit Rating Agencies" (IOSCO, 2004, p. 8) states: "Where feasible and appropriate, prior to issuing or revising a rating, the CRA should advise the issuer of the critical information and principal considerations upon which a rating will be based and afford the issuer an opportunity to clarify any likely factual misperceptions or other matters that the CRA would wish to be made aware of in order to produce an accurate rating. The CRA will duly evaluate the response". ${ }^{11}$ This guidance encourages CRAs to consult with local government officials prior to an announcement, but it recognizes that local oversight committees can choose not to (fully) implement the suggested guidelines based on the environment in which they operate (e.g., Bhattacharya and Daouk, 2002). ${ }^{12}$

Today, consultation between CRAs and local government officials is common practice when sovereign ratings are being revised. CRAs and regulators generally strive to maintain the confidentiality of information exchanged during the consultation process ahead of the public announcement. ${ }^{13}$ However, while a lower bound on the consultation time frame has been specified in some countries (e.g., 24 hours in the EU; see EU, 2013), in most cases an upper bound on this time frame is not specified, increasing the likelihood of information leakage. We expect that if there is information leakage and trading before the official announcement of a sovereign rating change, the rated entity's stock market experiences abnormal stock market reactions before the official announcement. ${ }^{14}$ Given the asymmetric stock market reactions between upgrades and downgrades (e.g., Berwart, Guidolin and Milidonis, 2014; Milidonis, 2013; and references therein), and in particular the much larger effect associated with downgrades, we focus on downgrade announcements. Further, because countries with lower institutional quality are less likely to adopt and fully enforce global standards, we expect that information leakage ahead of the official announcement is more likely to happen in countries with lower institutional quality, that is, pre-announcement negative abnormal stock market reactions are more likely to be associated with lower institutional quality.

\footnotetext{
${ }^{11}$ In the case of the US downgrade, S\&P reportedly made a calculation error that was corrected by Treasury officials before the downgrade announcement, but the S\&P continued to publish the downgrade. See http://www.treasury.gov/connect/blog/Pages/Just-the-Facts-SPs-2-Tril lion-Mistake.aspx.

12 In a revised document, IOSCO (2008) recommends increased transparency by CRAs in justifying their rating actions but does not provide additional guidelines on the consultation process between CRAs and government officials. The update does emphasize, however, that CRA employees should treat information in a strictly confidential manner (Section 3b).

${ }^{13}$ For instance, CRAs' websites highlight the importance of maintaining the confidentiality of information discussed with government officials of the sovereign entity (S\&P's, 2013), while regulatory efforts to safeguard the confidentiality of information related to upcoming rating actions include CESR (2004), IOSCO (2008), EU (2009, 2013), and ESMA (2013).

${ }^{14}$ Such leakage of information could be intentional or unintentional, and trading on it could be legal or illegal (Bhattacharya, 2014).
} 
An alternative explanation for negative abnormal reactions before official downgrade announcements would be the presence of concurrent bad news unrelated to the downgrade, such as macro, political, or any other marketmoving bad news. If there is a large amount of 'unrelated news' prior to the downgrade, the information leakage story is less likely to hold.

To test whether unrelated news or information leakage explains negative pre-announcement abnormal stock returns, we classify leakages into two mutually exclusive types. Cases in which the news contains rumors of a forthcoming downgrade before the official downgrade announcement are classified as 'observed leakages' and leakages that do not show up in the news are classified as 'unobserved leakages'. In the absence of both sovereign rating rumors (i.e., observed leakages) and unrelated news before the downgrade, a negative pre-announcement abnormal stock market reaction is attributed to unobserved leakages.

\section{Data and descriptive statistics}

In this section we describe the data collection process, state the sources used and provide descriptive statistics for the main variables. These are the sovereign ratings changes (Subsection 3.1), daily stock prices (Subsection 3.2), the institutional quality variables (Subsection 3.3), and the news related variables (Subsection 3.4).

\subsection{Sovereign ratings, outlooks, and watchlist inclusions}

The data set comprises the universe of sovereign ratings, outlook, and watchlist changes by the three largest CRAs, namely, Fitch, Moody's, and S\&P, from February 1988 to March 2012. These CRAs hold a substantial fraction of the market but have recently come under intense scrutiny (SEC, 2003, 2008; Beaver, Shakespeare and Soliman, 2006; Cheng and Neamtiu, 2009). While all three CRAs publish letter ratings, those of S\&P and Fitch differ from the letter grades of Moody's. Following prior bond rating literature (e.g., Beaver, Shakespeare and Soliman, 2006), we transform letter grades of S\&P and Fitch (Moody's) as follows: $\mathrm{AAA}(\mathrm{Aaa})=1 ; \mathrm{AA}+(\mathrm{Aa} 1)=2 ; \mathrm{AA}(\mathrm{Aa} 2)=3 ; \mathrm{AA}-(\mathrm{Aa} 3)=$ $4 ; A+(A 1)=5 ; A(A 2)=6 ; A-(A 3)=7 ; B B B+(B a a 1)=8$; $\mathrm{BBB}(\mathrm{Baa} 2)=9 ; \mathrm{BBB}-(\mathrm{Baa} 3)=10 ; \mathrm{BB}+(\mathrm{Ba} 1)=11 ; \mathrm{BB}$ $(\mathrm{Ba} 2)=12 ; \mathrm{BB}-(\mathrm{Ba} 3)=13 ; \mathrm{B}+(\mathrm{B} 1)=14 ; \mathrm{B}(\mathrm{B} 2)=15 ; \mathrm{B}-$ $(\mathrm{B} 3)=16 ; \quad \mathrm{CCC}+(\mathrm{Caa} 1)=17 ; \quad \mathrm{CCC} \quad(\mathrm{Caa} 2)=18 ; \quad \mathrm{CCC}-$ $(\mathrm{Caa} 3)=19 ; \mathrm{CC}(\mathrm{Ca})=20$; and $\mathrm{C}(\mathrm{C})=21$. In the case of actions related to sovereign financial distress and default (i.e., ratings of $\mathrm{D}, \mathrm{RD}, \mathrm{SD}$, etc.), we assign the value 22 .

We identify changes in (local and foreign currency) ratings and outlooks by comparing consecutive letter grades for each country. The samples for Fitch, Moody's, and S\&P begin in 1994, 1986, and 1983, with 318 (201), 336 (185), and 434 (350) changes in ratings (outlooks and watchlist inclusions), respectively. ${ }^{15}$ To test market

${ }^{15}$ For the remainder of the paper, "outlooks" also refer to watchlist inclusions. reactions around the announcement of ratings changes, we match the union of these rating changes with the panel of daily prices for each country's local currency stock market index and the MSCI World index from Datastream. Our analysis begins with the earliest date of the MSCI World index (January 1988) and ends one month after the last change in rating or outlook (March 2012). After removing duplicate events (i.e., ratings changes on the same day) and events with no index return data, the sample of ratings changes has 874 events (456 upgrades and 418 downgrades) for 65 countries, and the sample of outlook changes consists of six hundred events (334 positive and 266 negative).

Fig. 2, Panel A, reports the number of changes in sovereign debt ratings for the three largest CRAs (Fitch, Moody's, and S\&P). Downgrades appear to be more concentrated than upgrades and tend to happen during recessions or periods of global financial turmoil. The 1997 East Asian crisis, the 1998 Russian crisis, the 2001 US recession, and the global financial crisis starting in 2008 figure prominently in the number of downgrades.

Multiple ratings for the same sovereign around the same time are unlikely to have the same impact on local market returns because they are not independent of each other; that is, they are based in large part on the same information about the sovereign. Intuitively, the first rating or outlook change should be more informative for the stock market than changes occurring soon thereafter. To mitigate problems arising from crosssectional correlation across rating actions, we follow prior research (e.g., Martell, 2005) and use a first mover filter to construct a First Mover using Ratings (FMR) sample. The FMR sample comprises ratings changes for a sovereign not preceded by another change in rating by any CRA in the previous 20 trading days. This filter yields an event sample of 293 downgrades (from an initial 418) and four hundred upgrades (from an initial 456) from 65 countries.

Fig. 2, Panel B, plots the time series distribution of the FMR sample. Comparing Panels A and B, limiting attention to first mover announcements matters, as a substantial number of rating changes are removed, especially during recessions or periods of financial turmoil (1997, 1998, 2001, 2008 and 2011). In sensitivity analysis, we vary the number of days used to define a first mover. Fig. 3 plots the grade-level distribution after the rating change (downgrade or upgrade) both for the FMR sample and for each of the CRAs. The graphs show that rating changes (downgrades and upgrades) are not clustered on specific grade levels.

Outlook changes could also be informative about future changes in ratings. Thus, for robustness we also consider changes in outlooks. To do so, we first take the union of changes in ratings and outlooks and apply the first mover filter. We then construct two samples: (1) the First Mover using Ratings and Outlooks (FMRO) sample, which comprises changes in ratings or outlooks not preceded by another change in rating or outlook by any CRA in the 20 trading days prior to the event, and (2) the ratings-only FMRO sample, which comprises 

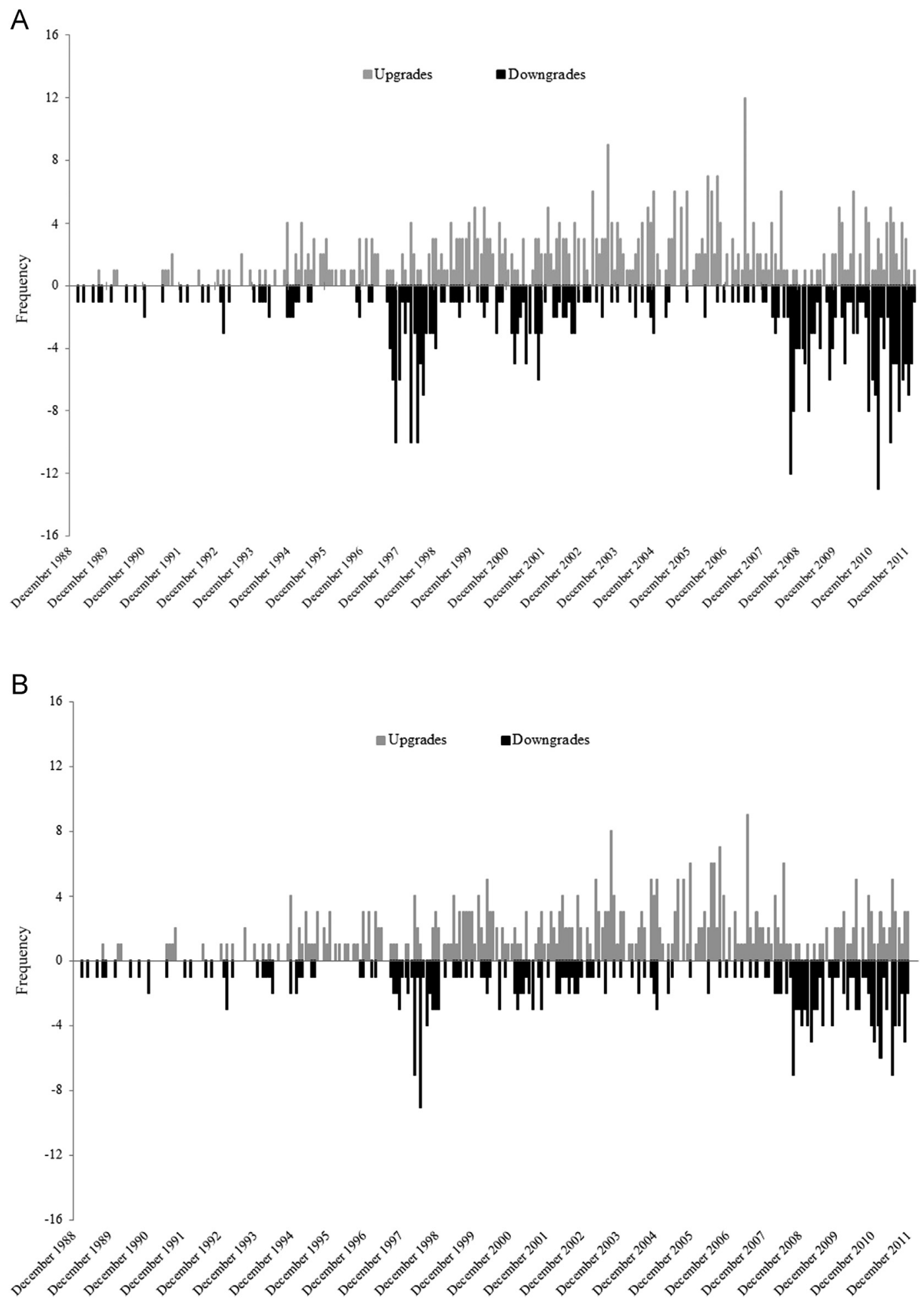

Fig. 2. Time series distribution of changes in sovereign ratings. Panel A shows all changes in ratings by Fitch, Moody's and Standard \& Poor's over time. The sample comprises 456 upgrades and 418 downgrades for 65 countries. Panel B shows the changes in ratings that are free from other changes in ratings from the same or another rating agency in the previous 20 days [First Mover using Ratings (FMR) sample]. These are made of four hundred upgrades and 293 downgrades from 65 countries. 
changes in ratings not preceded by another change in rating or outlook in the 20 trading days prior to the event.

\subsection{Daily stock market data}

We collect daily aggregate stock index data from Datastream. To maximize coverage, we employ the widely used MSCI indices, which are available for 65 countries in our sample. We require that each rating change have at least 60 daily observations in the estimation period (from day -270 to day -21$)$. This filter removes a few more observations from our dataset, thus giving 397 upgrades and 291 downgrades.

\subsection{Institutional quality variables}

We use TI's Corruption Perceptions Index to proxy for institutional quality. The TI index, which ranks more than 170 countries by their perceived levels of corruption as determined by expert assessments and opinion surveys, has been widely credited with putting the issue of corruption on the international policy agenda. The index is available annually since 1995 , and it ranges from 0 (very corrupt) to 10 (almost no corruption). We use the 1995 values for events prior to 1995.

For robustness, we employ other measures of institutional quality. In particular, we use a country's legal origin (common versus civil law) from La Porta, Lopezde-Silanes, Shleifer, and Vishny (1998); World Bank development classification (developed versus emerging and frontier); and standing in the law and order index from Political Risk Services Group (PRS). Because the TI index includes elements of these alternative measures, and because our main results are qualitatively similar using all measures, we report results only for the TI index.

To address potential endogeneity or errors-in-variables problems in the institutional quality proxies, we identify appropriate instrumental variables. We select from the following list: a country's legal origin (common versus civil law) from La Porta, Lopez-de-Silanes, Shleifer, and Vishny (1998), the ethnicity and religion fractionalization measures developed by Alesina, Devleeschauwer, Easterly, Kurlat, and Wacziarg (2003), and a landlocked indicator (Easterly and Levine, 2003).
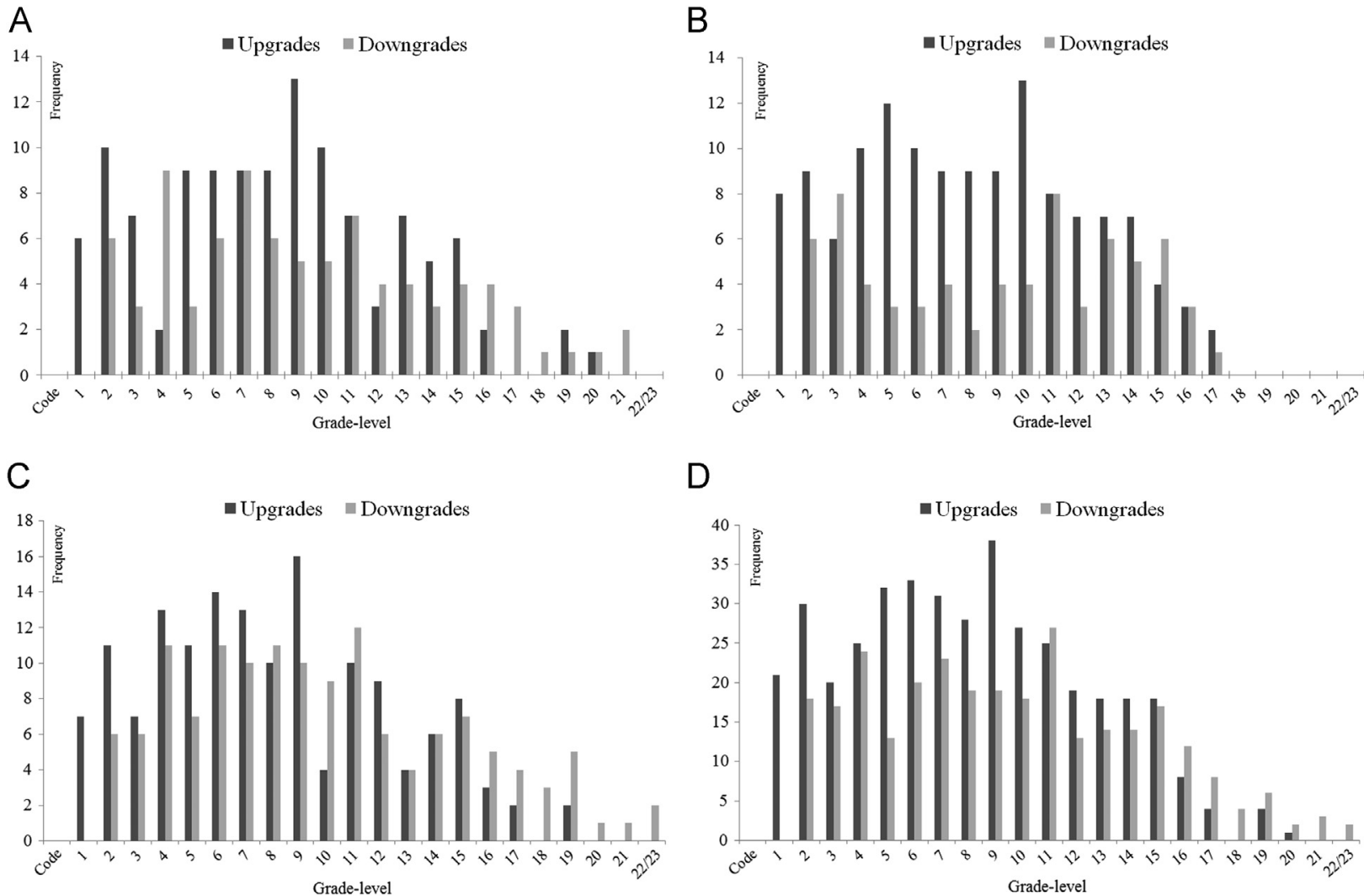

Fig. 3. Grade-level distribution of changes in sovereign ratings. A change in rating is defined by either a change in the local or foreign currency rating. The First Mover using Ratings (FMR) sample comprises changes in ratings by all rating agencies (changes in outlooks are excluded), which are not preceded by other changes in ratings by the same or other rating agencies in the previous 20 trading days. Panel A plots the 117 upgrades and 86 downgrades by Fitch; Panel B, the 133 upgrades and 70 downgrades by Moody's; Panel C, the 150 upgrades and 137 downgrades by Standard \& Poor's; and Panel D, the four hundred upgrades and 293 downgrades for the FMR sample. The horizontal axis shows the categories of ratings after the rating change is completed (higher numbers indicate lower debt quality). 


\subsection{News analysis}

To distinguish between the information leakage (observed or unobserved) versus unrelated news explanations, we follow a two-step approach. First, we conduct a manual news search before each announcement to identify sovereign downgrade news (Subsection 3.4.1) related to the forthcoming downgrade (i.e., observed leakages or rumors). Second, we use the country-level Thomson Reuters Marketpsych Indices to capture the frequency and content of economic, political, and other news that could affect investor sentiment (Subsection 3.4.2).

\subsubsection{Sovereign downgrade news}

We classify leakages as observed (i.e., traceable in the news) or unobserved. To identify observed leakages, we manually search LexisNexis for news stories prior to each downgrade announcement in which sovereign debt downgrades are rumored to be forthcoming. We look for news stories that contain the country name, along with the keyword "downgrade(s)" and the name of the CRA (including spelling variations) that makes the announcement. An example of a relevant news story is the Friday, March 6, 1998 Wall Street Journal piece that said "A top Russian central bank official signals that Fitch IBCA and Moody's Investors Service might lower their ratings on Russia's foreign debt, but says foreign money is still pouring into Russian bond market" (Wall Street Journal, 1998, Section A, p. 11). Moody's downgraded Russian sovereign debt on Wednesday, March 11, 1998, four trading days after the observed leakage.

We record the number of news stories in LexisNexis over the event window $(-10,-1)$. We then read each news story and identify rumors of forthcoming downgrades. The indicator variable Sovereign Downgrade News (SDN) takes the value of one when a downgrade announcement is preceded by at least one relevant news item (i.e., rumor) over the ten days preceding the announcement and zero otherwise. About $40 \%$ of downgrade announcements have at least one relevant news item preceding them, thus providing initial evidence that information leakage is taking place and is recorded in the news.

\subsubsection{Thomson Reuters MarketPsych Indices}

We complement our manual news search using the newly developed Thomson Reuters MarketPsych Indices (TRMIs). Thomson Reuters in collaboration with MarketPsych LLC use a proprietary algorithm that identifies news stories from Thomson Reuters News Feed Direct, Factiva News, and other third party news sources to construct daily country-specific indices for the frequency (TMRI Buzz) and content (TRMI Sentiment) of news related to the country of interest. Because the TRMIs are based on the universe of news related to a country on a daily basis, by construction they include not only news related to a forthcoming downgrade, but also other news unrelated to the downgrade. TRMI Buzz and TRMI Sentiment are available as of 1998.

For each country-day, TRMI Buzz reports the number of news stories related to macroeconomic announcements (internal or external), political influence, and other exogenous factors (e.g., natural disasters). Buzz is estimated using a 24four hour rolling window. To reduce the impact of outliers in the Buzz variable (skewness=17.19; kurtosis=364.30), we use the log of Buzz (skewness=0.18; kurtosis=1.14).

To construct daily measures of TRMI Sentiment, a proprietary algorithm reads the content of each story relevant to a country of interest and scores it on a normalized scale between -1 and 1 . In the finance literature, researchers (e. g., Tetlock, Saar-Tsechansky, and Macskassy, 2008) create proxies for sentiment using positive and negative references in the news. TRMI Sentiment builds on this approach, using a multi-dimensional proxy for investor sentiment that captures the overall tone of the article as well as that of specific words present in macroeconomic, political, and other news. ${ }^{16}$ Hence, TRMI Sentiment transforms news articles based on their general tone and specific word choice into an index between -1 to +1 that is positively correlated with market sentiment. ${ }^{17}$ This transformation is intended to capture not only macro-related information, and other general news relevant to each country, but also feelings such as joy or fear that could affect stock market reactions (e.g., Stambaugh, Yu, and Yuan, 2012).

\section{Event study analysis: Do stock markets around the world move before official announcements?}

In this section we describe the methodology used to test if stock markets move before official announcements (Subsection 4.1), and provide the results (Subsection 4.2), and robustness checks (Subsection 4.3).

\subsection{Methodology}

To examine the impact of changes in sovereign debt ratings and outlooks on local stock index returns, we use short-horizon event study analysis, an approach that is "relatively straightforward and trouble-free" according to the recent study by Kothari and Warner (2007, p. 8) on the econometrics of event studies. We regress each country's major stock index returns, as estimated by a market model, on the MSCI World index returns over the period [ - 270,-21] relative to event day $0 .{ }^{18}$ We then calculate abnormal returns over the $[-20,+20]$ event period as the difference between actual index returns and expected returns. Given the importance of standard errors in our analysis, we use the methodology of Kolari and Pynnonen (2010) for our baseline case, as it addresses both event-induced variance and cross-sectional correlation in abnormal returns. More details on our methodology are provided in the Appendix.

\footnotetext{
${ }^{16}$ For more information, see MarketPsych LLC's website: https:// www.marketpsych.com/.

17 We estimate the correlation between daily observations of TRMI Sentiment and daily raw returns for all events in our sample including the estimation period for each event. The correlation is positive $(0.1173)$ and statistically significant ( $p$-value $<0.001$ ), supporting the validity of TRMI Sentiment.

${ }^{18}$ We do not have the exact timing of the rating announcement, that is, whether it happens before or after the close of business on the event date. We, therefore, use the window $[0,1]$ to capture the announcement effect.
} 
Table 1

Event study of changes in sovereign ratings on local stock market indices.

This table presents event-study results of how sovereign debt rating changes affect the respective sovereign daily, stock market return. Results are reported separately for upgrades $(n=397)$ and downgrades $(n=291)$. The sample comprises the union of changes in ratings, from Fitch, Moody's, and Standard and Poor's, using ratings FMR (First Mover using Ratings) sample. The FMR sample comprises ratings changes for a sovereign not preceded by another change in rating by any CRA in the previous 20 trading days. Panel A shows daily average abnormal returns on day $t$, AAR $(t)$. Panel B shows the cumulative average abnormal return, CAAR $\left[t_{1}, t_{2}\right]$, starting on $t_{1}$ and ending at $t_{2}$ relative to event day (day 0 ). $p$-values are based on Kolari and Pynnonen (2010). ***,**, and * denote statistical significance (SS) at the $1 \%, 5 \%$, and $10 \%$ level, respectively.

Panel A: Average abnormal returns (AARs)

\begin{tabular}{|c|c|c|c|c|c|c|}
\hline \multirow[b]{2}{*}{ Relative day } & \multicolumn{3}{|c|}{ Upgrades } & \multicolumn{3}{|c|}{ Downgrades } \\
\hline & AAR (percent) & $p$-value & SS & AAR (percent) & $p$-value & SS \\
\hline-10 & -0.070 & 0.328 & & -0.033 & 0.808 & \\
\hline-9 & 0.005 & 0.694 & & -0.197 & 0.189 & \\
\hline-8 & 0.018 & 0.637 & & -0.310 & 0.143 & \\
\hline-7 & -0.165 & 0.211 & & -0.123 & 0.179 & \\
\hline-6 & -0.039 & 0.549 & & -0.172 & 0.096 & $*$ \\
\hline-5 & -0.016 & 0.267 & & -0.236 & 0.039 & $* *$ \\
\hline-4 & 0.106 & 0.239 & & -0.294 & 0.016 & $* *$ \\
\hline-3 & 0.172 & 0.116 & & -0.275 & 0.077 & $*$ \\
\hline-2 & -0.085 & 0.170 & & 0.062 & 0.199 & \\
\hline-1 & -0.087 & 0.238 & & -0.313 & 0.016 & $* *$ \\
\hline 0 & 0.079 & 0.173 & & -0.236 & 0.035 & $* *$ \\
\hline 1 & 0.112 & 0.097 & $*$ & -0.338 & 0.019 & $* *$ \\
\hline 2 & -0.217 & 0.032 & $* *$ & 0.150 & 0.491 & \\
\hline 3 & -0.157 & 0.194 & & 0.469 & 0.159 & \\
\hline 4 & -0.055 & 0.525 & & 0.306 & 0.041 & $* *$ \\
\hline 5 & 0.002 & 0.786 & & 0.074 & 0.768 & \\
\hline 6 & -0.121 & 0.044 & $* *$ & 0.352 & 0.014 & $* *$ \\
\hline 7 & -0.090 & 0.261 & & 0.305 & 0.081 & $*$ \\
\hline 8 & -0.150 & 0.119 & & 0.177 & 0.206 & \\
\hline 9 & -0.083 & 0.719 & & -0.138 & 0.144 & \\
\hline 10 & -0.015 & 0.807 & & -0.441 & 0.168 & \\
\hline \multicolumn{7}{|c|}{ Panel B: Cumulative average abnormal returns (CAARs) } \\
\hline & \multicolumn{3}{|c|}{ Upgrades } & \multicolumn{3}{|c|}{ Downgrades } \\
\hline Event window & CAAR (percent) & $p$-value & SS & CAAR (percent) & $p$-value & SS \\
\hline$(-10,-3)$ & 0.011 & 0.471 & & -1.641 & 0.000 & $* * * *$ \\
\hline$(-5,-3)$ & 0.262 & 0.024 & $* *$ & -0.806 & 0.001 & $* * * *$ \\
\hline$(0,+1)$ & 0.191 & 0.030 & $* *$ & -0.574 & 0.002 & $* * * *$ \\
\hline$(+2,+5)$ & -0.427 & 0.026 & $* *$ & 1.000 & 0.046 & $* *$ \\
\hline$(+2,+10)$ & -0.886 & 0.003 & $* * *$ & 1.254 & 0.402 & \\
\hline$(-5,+5)$ & -0.145 & 0.992 & & -0.631 & 0.028 & $* *$ \\
\hline$(-10,+10)$ & -0.856 & 0.207 & & -1.212 & 0.014 & $* *$ \\
\hline
\end{tabular}

\subsection{Empirical results}

Table 1, Panel A, reports daily average abnormal returns for event window $[-10,+10]$, along with their statistical significance following Kolari and Pynnonen (2010). Results are reported for both upgrades and downgrades using the FMR sample. ${ }^{19}$ Several observations stand out.

First, we observe more days with significant stock market reactions around downgrades than upgrades. Second, the economic impact of downgrades appears to be significantly higher than that of upgrades, especially prior to the announcement. Third, both upgrades and downgrades exhibit

\footnotetext{
${ }^{19}$ We also experiment with separately testing ratings changes beyond one notch, as changes greater than one notch could have a larger market effect than single-notch changes. We did not find statistically different results and, therefore, report results without differentiating the number of notches.
}

a market reaction in the expected direction over event window [0,1], which is again larger for downgrades. The significant abnormal stock market decline prior to downgrade announcements suggests that the case of Cyprus (Fig. 1) is part of a global trend of pre-event stock market reactions ahead of official sovereign debt rating announcements. The results are also consistent with prior literature that finds larger absolute market reactions to downgrades than upgrades. We also observe a statistically significant reversal for both upgrades and downgrades starting right after the announcement. In Subsection 5.4 we provide a more detailed look at reversals.

Table 1, Panel B, and Fig. 4 present cumulative average abnormal returns (CAARs) over different event windows. For downgrades, we find an economically and statistically significant negative market reaction in the pre-announcement period (CAAR $[-5,-3]=-0.81 \%$ with $p$-value $<0.01$; CAAR $[-10,-3]=-1.64 \%$ with $p$-value $<0.01)$, as well as a 
CAARs for changes in sovereign debt ratings (Ratings FMR sample)

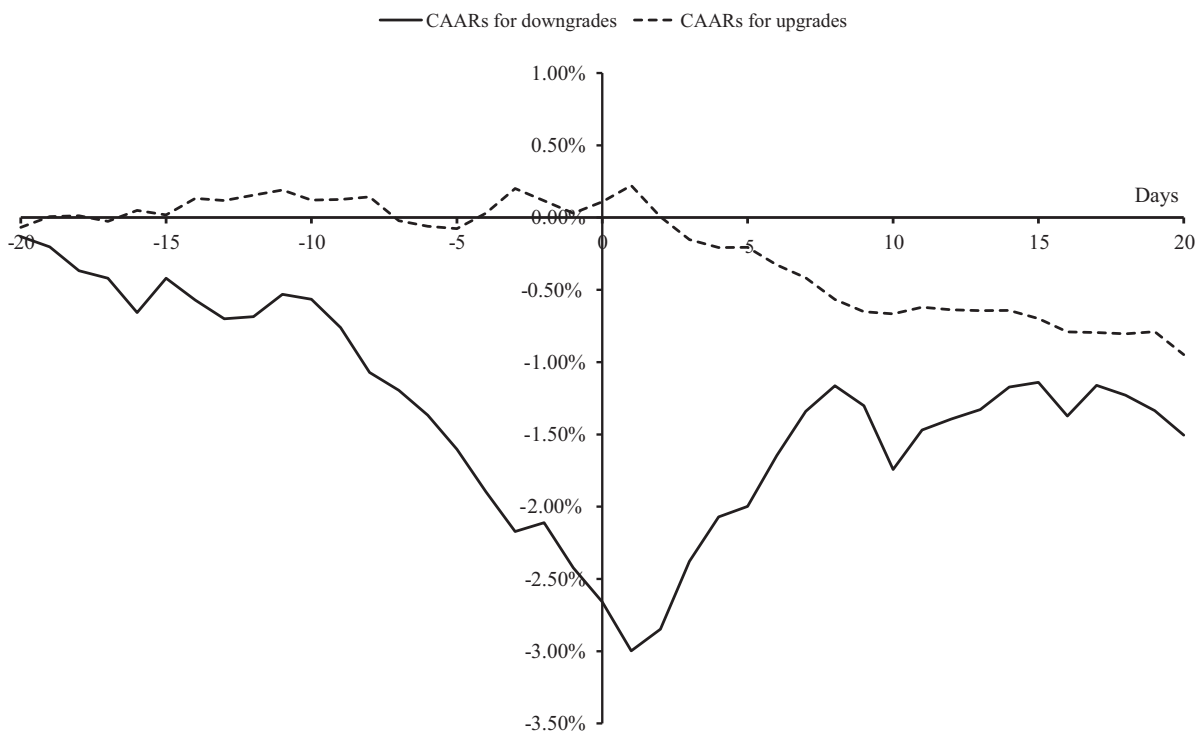

Fig. 4. Cumulative average abnormal returns (CAARs) for changes in sovereign ratings. The graph shows market-adjusted cumulative average abnormal returns for the ratings FMR (First Mover using Ratings) sample: 397 upgrades and 291 downgrades. The FMR sample comprises ratings changes for a sovereign not preceded by another change in rating by any CRA in the previous 20 trading days.

A

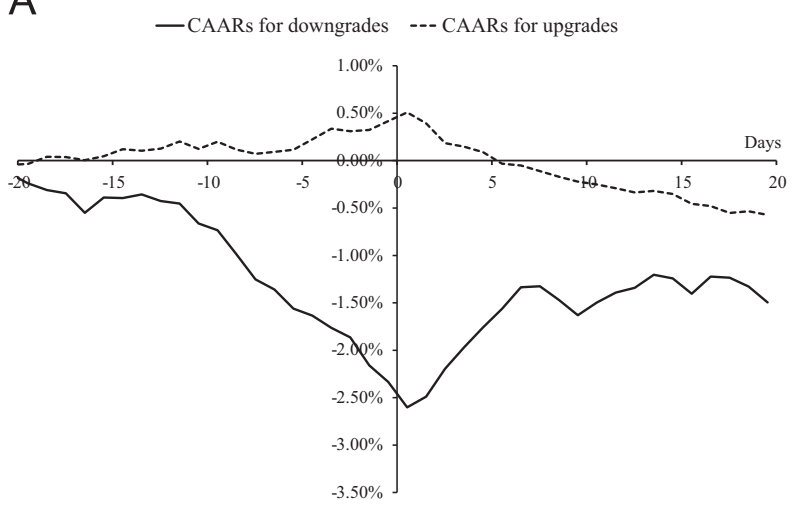

C

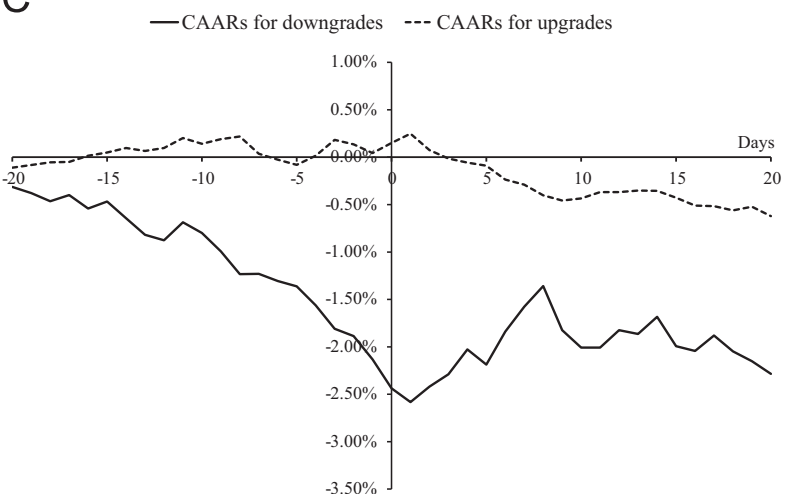

B

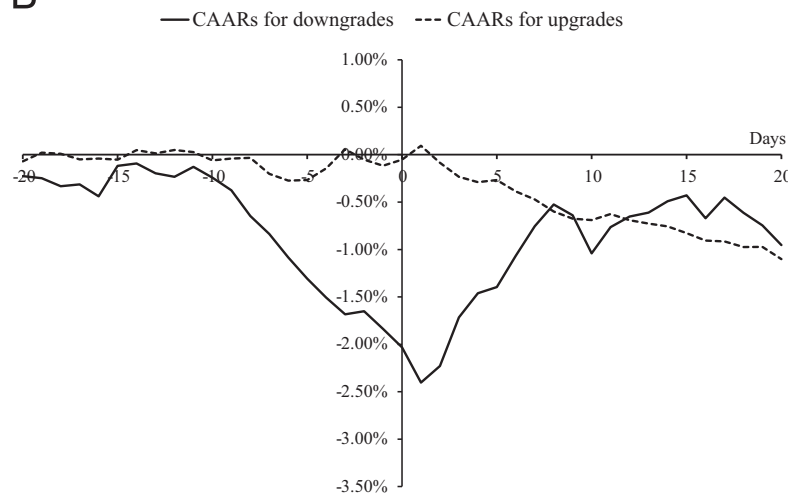

$\mathrm{D}$

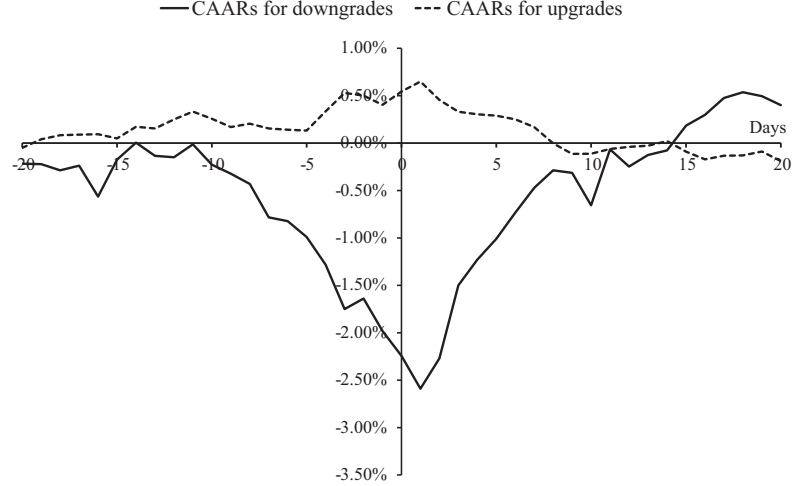

Fig. 5. Cumulative average abnormal returns (CAARs) for changes in sovereign ratings: robustness. This figure presents robustness tests of cumulative average abnormal returns of the baseline case of the ratings FMR (First Mover using Ratings) sample. The FMR sample comprises ratings changes for a sovereign not preceded by another change in rating by any CRA in the previous 20 trading days. Panel A shows CAARs for the FMRO sample (667 upgrades and 483 downgrades). FMRO (First Mover using Ratings and Outlooks) is a first mover filter using ratings and outlooks in the previous 20 days. Panel B shows the ratings only FMRO sample (378 upgrades and 255 downgrades), which is the union of ratings filtered using the ratings and outlooks filter (FMRO). Panel C shows CAARs for the union of ratings but without the First Mover filter (453 upgrades and 415 downgrades). Panel D shows the same sample as A, but excluding the recent financial crisis (315 upgrades and 161 downgrades). 
significant negative announcement effect $(-0.57 \%) .{ }^{20}$ In the post-announcement period (CAAR $[+2,+5])$, we find a statistically significant positive reaction of $1 \%$ ( $p$ value $<0.05$ ), but it does not persist. The overall effect for downgrades as measured by CAAR $[-5,+5]$ (CAAR $[-10,+10])$ is $-0.63 \%(11.21 \%)$ and statistically significant. For upgrades, weaker evidence exists of positive abnormal returns in the pre-announcement period and no significant effect over the ten or 20 days around an announcement. Because the economic significance of stock market reactions around downgrades is greater than that around upgrades, we focus on downgrades in our analysis on what explains the announcement period abnormal returns.

\subsection{Robustness}

Before examining whether information leakage (Section 5) or concurrent unrelated bad news (Section 6) explains the announcement period abnormal returns we show above, we conduct several tests to verify the robustness of these results.

First, we test whether changes in outlooks and watchlist inclusions are also informative about future ratings changes. To do so, we repeat our analysis using two alternative samples: the FMRO sample and the ratingsonly FMRO sample. Panels A and B of Fig. 5 plot marketadjusted announcement period CAARs for these samples. Results are similar to those based on the FMR sample, both in economic and statistical significance (unreported). ${ }^{21}$

Second, we examine whether our results hinge on our definition of first mover. To do so, we repeat the analysis using all CRA changes (i.e., not applying the first mover 20day filter). The results, displayed in Fig. 5, Panel C, show that our conclusions remain unchanged (downgrades show substantial pre-announcement stock market effects, with partial reversal after the announcement, while upgrades show weaker effects). Hence, our findings are not sensitive to the definition of first mover.

Another potential concern is the presence of higher stock market volatility during recessions, which could be linked to an increased number of downgrades (as Fig. 2 suggests). For example, downgrades reached a peak in October 2008, during the particularly volatile Great Recession. To address potentially confounding effects during recessionary periods, we repeat the analysis excluding all events after December 31, 2007, focusing on the FMR sample of rating changes during the Great Moderation (1989-2007). The results, presented in Fig. 5, Panel D, are again similar to our baseline results (Fig. 4), indicating that the event study patterns we find are not driven by the recent financial crisis. ${ }^{22}$

\footnotetext{
${ }^{20}$ For the pre-event window we focus primarily on the $[-5,-3]$ window, but we also consider the $[-10,-3]$ window because ESMA (2013, p. 12) finds that in some instances, ratings were published "more than five days after the rating decision had been approved by the rating committee and, in at least one case even two weeks after the date of the committee".

${ }^{21}$ Results referred to as "unreported" are available in the online appendix.

${ }^{22}$ Results are also robust to using the FMRO and ratings-only FMRO samples.
}

Finally, we address potential illiquidity problems due to including emerging and frontier markets in the analysis. Following Lesmond, Ogden, and Trzcinka (1999) and Bekaert, Harvey, and Lundblad (2007), we use the percentage of zero returns as a proxy for illiquidity. Specifically, we exclude events that have more than ten days of zero returns over the $[-20,+20]$ testing period. Our results are not affected by this filter.

\section{Can information leakage explain the pre- announcement period abnormal returns?}

Why do stock markets around the world decline before official sovereign downgrade announcements? We hypothesize that information leakage about a forthcoming downgrade during the consultation process between CRAs and local government officials can explain this pattern, with leakage effects stronger in countries with weaker institutions.

To test this hypothesis, we repeat the analysis above taking into account variation in institutional quality across countries. Our proxy for institutional quality is the Corruption Perception Index from Transparency International. We begin by taking a conservative approach and separating countries by the FMR sample's median TI index score. We then separate the sample of downgrades into those with high and low TI scores (where a high TI score indicates less corruption) and re-run our analysis for each sample. ${ }^{23}$

\subsection{Empirical results}

In Fig. 6 and Table 2 (first column) we report the CAARs for high and low TI downgrades. The results are striking: the pattern of abnormal returns around downgrade announcements that we observe in Section 4 is clearly driven by countries with low institutional quality. In particular, we find a negative and statistically significant CAAR $[-5,-3]$ of $-1.59 \%$ ( $p$-value $<0.01$ ) for high corruption (low TI score) countries and no significant effect for high TI score countries. For low TI score countries, the effect is also present in the longer $[-10,-3]$ pre-event window, with a CAAR of $-2.92 \%$ ( $p$-value $<0.01)$.

To test whether negative pre-announcement market returns are stronger for countries with weaker institutions, we run ordinary least squares (OLS) regressions of cumulative abnormal returns (CARs) using the TI score as an explanatory

\footnotetext{
${ }^{23}$ We classify our sample of downgrades into high and low TI by splitting at the median value of the annual transparency index. Countries consistently categorized as having low transparency are Brazil, Bulgaria, China, Colombia, Egypt, Ghana, India, Indonesia, Jamaica, Kazakhstan, Kenya, Mexico, Morocco, Nigeria, Pakistan, Philippines, Poland, Romania, Russian Federation, Sri Lanka, Thailand, Trinidad and Tobago, Turkey, Ukraine and Vietnam. Countries consistently categorized as having high transparency are Australia, Bahrain, Belgium, Canada, Chile, Cyprus, Estonia, Finland, Hong Kong, Hungary, Iceland, Ireland, Israel, Japan, Jordan, Korea, Latvia, Malaysia, New Zealand, Portugal, Slovenia, Spain, Sweden, Taiwan, and US. The following countries are classified as having high or low transparency depending on the year of the downgrade, because their TI score is close to the median: Argentina, Croatia, Czech Republic, Greece, Italy, Peru, South Africa, and Tunisia. Results are stronger if we compare the 25 th and 75 th percentiles. Source is www. transparency.org.
} 


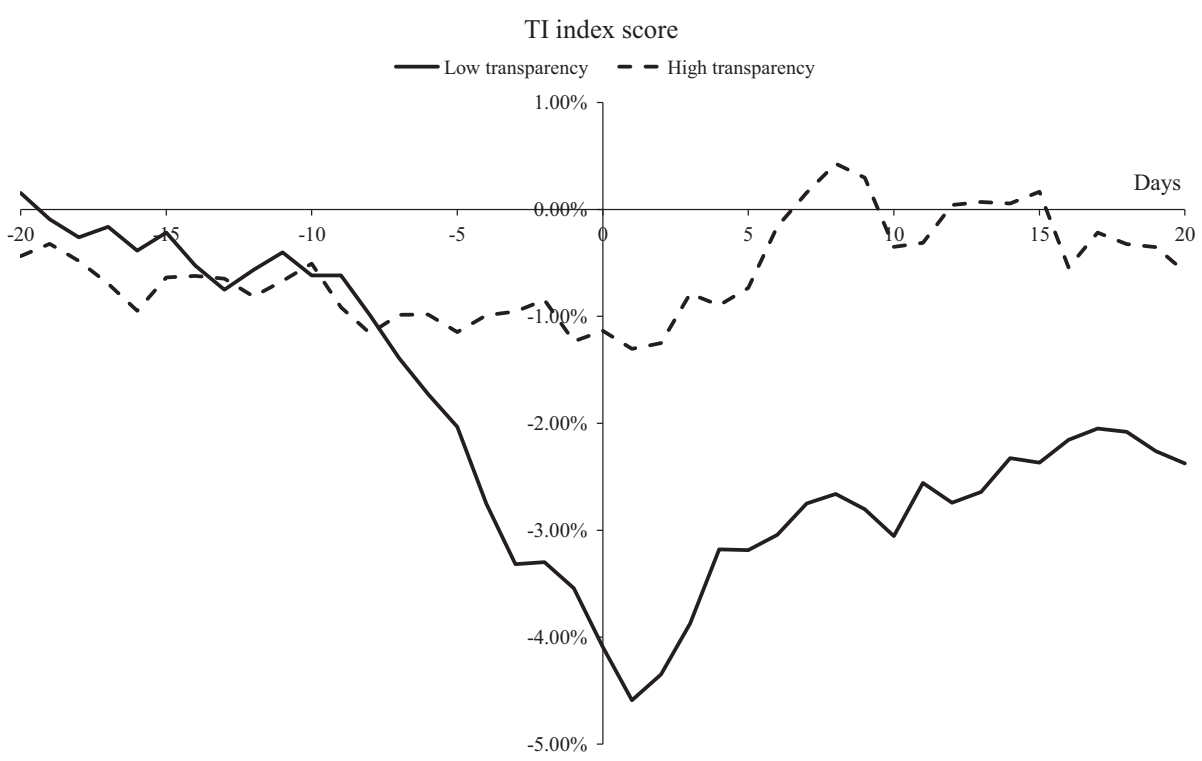

Fig. 6. Cumulative average abnormal returns (CAARs) for downgrades by institutional quality. The graph shows the cumulative average abnormal returns for downgrades in sovereign ratings, according to the Transparency International (TI) Corruption Perception Index [ratings FMR (First Mover using Ratings) sample]. There are a total of 149 with low TI (high corruption) and 142 events with high TI (low corruption) score. The separation of each category is made at the median value of the "Ratings FMR" sample.

\section{Table 2}

Cumulative abnormal returns (CARs) for downgrades by institutional quality.

The table presents the impact of sovereign debt downgrade announcements on the respective local stock market index, using the ratings FMR (First Mover using Ratings) sample, conditional on institutional quality. The FMR sample comprises ratings changes for a sovereign not preceded by another change in rating by any CRA in the previous 20 trading days. CAAR $\left[t_{1}, t_{2}\right]$ is the cumulative average abnormal return (in percent) for the period starting on $t_{1}$ and ending at $t_{2}$ relative to event day (day 0 ). We use the Transparency International (TI) Corruption Perception index to proxy for institutional quality. We present CAARs separately for downgrades with high TI and low TI (low TI implies low institutional quality) scores. The separation of each category is made at the median value of the ratings FMR sample. $n$ is the number of observations in each subcategory. $p$-values are based on the Kolari and Pynnonen (2010) approach. $* * * * *$, and $*$ denote statistical significance (SS) at the $1 \%, 5 \%$, and $10 \%$ level, respectively. The table also reports ordinary least squares (OLS) regressions of CARs on the TI Corruption Perception Index, winsorized at the $1 \%$ level. The intercept of the OLS regression is not shown. Each regression has 291 observations. $p$-value is based on robust Huber-White standard errors.

\begin{tabular}{|c|c|c|c|c|c|c|c|c|c|}
\hline \multirow[b]{3}{*}{ Event window } & \multicolumn{6}{|c|}{ CAARs conditional on TI score } & \multirow{2}{*}{\multicolumn{3}{|c|}{$\frac{\text { OLS regression of CARs on TI score }}{\text { TI score }}$}} \\
\hline & \multicolumn{3}{|c|}{ Low TI score $(n=149)$} & \multicolumn{3}{|c|}{ High TI score $(n=142)$} & & & \\
\hline & CAAR (percent) & $p$-value & SS & CAAR (percent) & $p$-value & SS & Coefficient & $p$-value & SS \\
\hline$(-10,-3)$ & -2.915 & 0.000 & $* * * *$ & -0.286 & 0.522 & & 0.004 & 0.023 & $* *$ \\
\hline$(-5,-3)$ & -1.589 & 0.000 & $* * * *$ & 0.028 & 0.894 & & 0.003 & 0.020 & $* *$ \\
\hline$(0,+1)$ & -1.047 & 0.001 & $* * *$ & -0.070 & 0.202 & & 0.002 & 0.057 & * \\
\hline$(+2,+5)$ & 1.404 & 0.010 & $* * * *$ & 0.569 & 0.767 & & -0.002 & 0.068 & * \\
\hline$(+2,+10)$ & 1.536 & 0.103 & & 0.954 & 0.931 & & 0.000 & 0.842 & \\
\hline$(-5,+5)$ & -1.458 & 0.018 & $* *$ & 0.250 & 0.427 & & 0.002 & 0.417 & \\
\hline$(-10,+10)$ & -2.652 & 0.004 & $* * * *$ & 0.321 & 0.392 & & 0.006 & 0.064 & * \\
\hline
\end{tabular}

variable and robust Huber-White standard errors (Table 2, third column). We expect that abnormal market reactions before an announcement are positively related to measures of institutional quality (i.e., we expect better institutional quality to be associated with less negative CARs). We find that the coefficient on TI score is positive and statistically significant for both pre-event windows ( $p$-value $<0.05$ ). Specifically, as the TI score decreases (corruption increases), there are more negative CARs before the announcement, consistent with more information leakage and subsequent trading on the leaked information in countries with higher corruption. Our findings also suggest that such leakage is destabilizing because there is a reversal after the event, indicating that the overall effect is not as large. The cross-sectional regression of CAR $[+2,+5]$ on TI score confirms that the reversal associated with downgrades increases with lower institutional quality. 


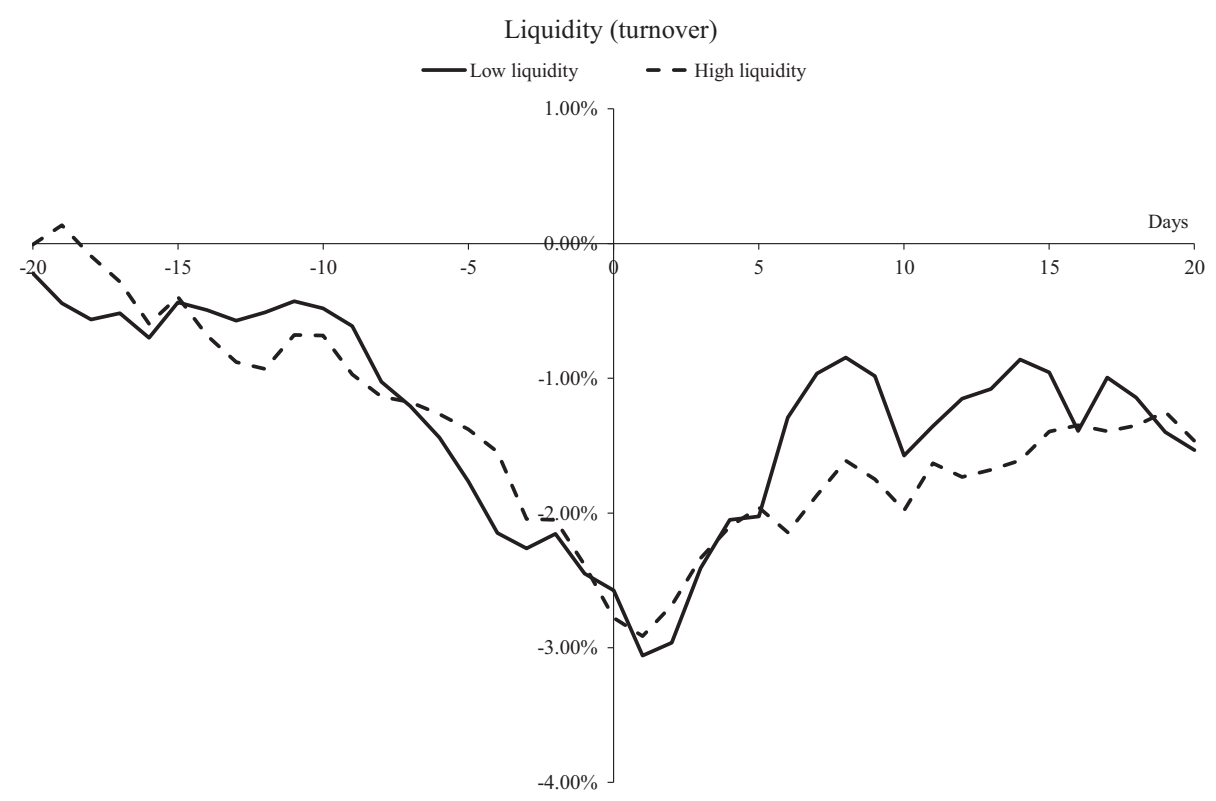

Fig. 7. Cumulative average abnormal returns (CAARs) for downgrades by turnover. The graph shows the cumulative average abnormal returns for sovereign rating downgrades, according to the level of liquidity [ratings FMR (First Mover using Ratings) sample].We proxy for liquidity by estimating daily turnover in the estimation and testing periods and then taking its time series average around each event. Turnover is the ratio of total market volume traded divided by market capitalization. High liquidity is downgrades with above median liquidity levels ( $n=169$ ). Low liquidity is downgrades with below median liquidity levels $(n=122)$.

\subsection{Robustness}

Cross-sectional differences in liquidity across countries could be associated with differences in stock market reactions and could, therefore, confound results. For example, illiquidity could be more likely in countries with lower institutional quality, exacerbating negative CARs in the pre-event period. To address this concern, we first proxy for liquidity using daily stock market turnover, that is, the total daily market volume traded divided by daily market capitalization over the estimation and testing periods. Then, for each event we calculate the time series average of daily turnover. We next estimate the median value across all upgrades and downgrades in our sample and classify an event as having low (high) liquidity if its time series average turnover is below (above) the population median. Fig. 7 shows that differences in liquidity do not affect our conclusions, because negative preannouncement abnormal returns are present in both the high and low liquidity samples. ${ }^{24}$ Another view is that illiquidity is a symptom of corruption, not an alternative explanation. If this were true, in Fig. 7 we would expect to see similar trends to those in Fig. 6 as liquidity would be highly correlated with institutional quality.

To address potential concerns that the assumption of Kolari and Pynnonen (2010) is violated (i.e., the event changes the residual correlation in the estimation period),

\footnotetext{
${ }^{24}$ Because the MSCI indices do not provide volume data, we use volume data from alternative country stock market indices from Datastream. Stock market reactions before, during and after rating changes using the alternative stock market indices with accompanying volume data are consistent with results using the MSCI indices (unreported).
}

we conduct panel regressions on daily returns separately for high and low TI events (unreported). First, we run a panel regression of daily stock returns on world returns and 21 dummy variables for each day in the $(-10,+10)$ event window with robust (White) standard errors clustered at the event level. Second, we add country fixed effects. Third, we add country-day fixed effects. We find that the negative abnormal returns before and the partial reversal after the announcement remain statistically and economically significant for low TI events.

Next, because low institutional quality events could exhibit increased volatility, our results could be due to higher volatility. To control for the volatility of stock returns, we replace abnormal returns with information (Sharpe) ratios constructed by dividing returns by their standard deviation over the estimation period. We then run panel regressions as described above and find that results continue to hold in all specifications (unreported). ${ }^{25}$

Our daily estimates of betas could be noisy and add uncertainty to our results. To address this concern, we use several variations of the market model to estimate abnormal returns (unreported). First, we set all country betas equal to one and re-run the analysis. Second, we use fullsample monthly betas in the estimation period market model, that is, the beta estimate is based on the entire time series of data available for a rated sovereign instead of only the year before the testing period. Third, we use raw returns in our estimations. Specifically, we calculate

\footnotetext{
${ }^{25}$ Splitting the sample into above and below investment-grade rating groups and controlling for volatility yields qualitatively similar results (unreported).
} 
average raw returns in the estimation period and subtract them from actual returns in the testing period to estimate abnormal raw returns (plain raw returns in the testing period are also used). As a final robustness check on the beta estimation, we estimate abnormal returns for countries highly correlated with the US market using a variation of the MSCI World index that excludes the US. For non-highly correlated sovereigns, we use the MSCI World index. We find that the results in Subsection 5.1 are robust to each of these specifications.

\subsection{Endogeneity}

Endogeneity can affect our results. For example, countries with more insider trading are more likely to be classified as low institutional quality and could be associated with a higher probability of information leakage. In such cases, institutional quality depends on abnormal stock return reactions to public announcements instead of the reverse. Thus, a positive correlation between pre- and post-event abnormal stock returns and institutional quality does not necessarily imply that institutional quality causally affects the abnormal return patterns we find. Errors-in-variables problems can also affect our conclusions. For example, a proxy for institutional quality could be an imperfect measure of true institutional quality, in which case regressing CARs on the proxy generates biased estimates depending on the degree of measurement error.

To address these problems and give a causal interpretation to the proven correlations, the classic solution is to employ instrumental variables (IVs). Accordingly, we conduct two-stage least squares regressions of pre- and postannouncement CARs on potentially endogenous proxies for institutional quality. We focus on TI for brevity. Results are similar using other measures of institutional quality [legal origin (common versus civil law) from La Porta, Lopez-de-Silanes, Shleifer, and Vishny (1998); World Bank development classification (developed versus emerging and frontier); and the PRS law and order index].

We start by identifying four candidate instruments for our regressors. First, we consider a country's legal origin, in which an indicator takes the value of one for a common law system and zero otherwise (La Porta, Lopez-de-Silanes, Shleifer, and Vishny, 1998). Next, we consider the ethnicity and religion fractionalization measures of Alesina, Devleeschauwer, Easterly, Kurlat, and Wacziarg (2003). Our fourth candidate instrument is the landlocked indicator of Easterly and Levine (2003). These four variables are arguably exogenous because they were determined many decades before the events we study. Moreover, legal origin, fractionalization, and geography are good candidates for random variation that could be correlated with the endogenous variables of interest (measures of institutional quality) but is not directly related to the dependent variable (CARs).

To identify the best instruments for TI index score, we follow Baum, Schaffer, and Stillman (2011) and test for model under identification (UID), weak identification (WID), and over identification (OID), as well as for redundancy of the IVs. We first assume that the four instruments are valid. The null under the redundancy test is that the instrument of interest is redundant. As shown in Table 3, Panel A, three of the four candidate instruments are valid
( $p$-values $<0.01$; Round 1 ). We repeat this procedure until no redundant instruments appear (Round 2). In the first step, we find that all but one candidate instrument (landlocked) is statistically significant at a $p$-value of $1 \%$ or better. Thus, in the second step, we omit this variable. Therefore, in the TSLS estimation, we employ three nonredundant IVs for TI score: common versus civil law, ethnic fractionalization, and religion fractionalization.

Results of the TSLS analysis for the pre-event period are reported in Table 3, Panel B, using CAR [-10,-3] and CAR $[-5,-3]$ as the dependent variables. As in the OLS analysis, we expect a positive coefficient on TI index score in the pre-event period. We find that the coefficient on TI score is positive and statistically significant for both preannouncement event windows. The results are economically significant as well, with a 1-standard deviation (2.1) decrease in the TI index leading to a $1.25 \%$ ( $p$-value $<0.01$ ) decrease in CAR over the $[-5,-3]$ period, when all identification tests are again satisfied. ${ }^{26}$

In unreported analysis we also find statistically and economically significant effects when we use the other proxies for institutional quality $(p$-values $<0.05)$. Specifically, emerging or frontier countries (using common law, ethnic fractionalization and landlocked as instruments) generate CARs that are $2.40 \%$ lower than those of developed countries, and the 1-standard deviation effects for the PRS law and order index (using common law and ethnic fractionalization as instruments) show a $0.86 \%$ decrease in CAR.

The statistical tests strongly reject under identification. With respect to the weak IV (WID) hypothesis, both the Cragg-Donald [for independent and identically distributed (i.i.d.) error disturbances] and Kleibergen-Paap (for non-i.i. d. errors) test statistics exceed the Staiger and Stock (1997) thresholds to reject the hypothesis of weak IVs. The CraggDonald and Kleibergen-Paap tests further reject the weak IV hypothesis when compared with the Stock and Yogo (2005) relative bias and relative size tests, though strictly speaking the values for the Kleibergen-Paap test should be compared with the i.i.d. case. We thus reject the weak IV hypothesis. The Hansen $J$-statistic does not reject overidentification at the $5 \%$ level. ${ }^{27}$

\subsection{Rumors and the post-announcement reversal}

In the Brunnermeier (2005) market microstructure model on the effects of information leakage and trading behavior on stock returns, the stock price reflects early informed traders' short-run signals of an upcoming news announcement (i.e., rumor) and other traders' unrelated long-run private information. Brunnermeier (2005) shows that traders with access to nonpublic information can exploit this information twice: by trading on this information before the actual public

\footnotetext{
${ }^{26}$ Results also hold using the FMRO and ratings-only FMRO samples.

27 We also test whether the post-event reversal is caused by institutional quality using the same procedure as above for the CAR $[+2,+5]$ window. Results using the TI index remain negative and statistically significant (at the 10\% level), but do not hold across the other measures of institutional quality we use. We defer a detailed investigation of the reversal to Subsection 5.4.
} 
Table 3

Two-stage least square (TSLS) regressions of cumulative abnormal returns (CARs) on institutional quality.

Panel A shows the selection process for instrumental variables (IVs) to be used for the endogenous regressor approximating institutional quality (Transparency International Index). The dependent variable is CAR [ -5, -3] winsorized at the $1 \%$ level (results are similar using CAR [ - 10, - 3], hence not shown). The four IVs tested are: common versus civil law (La Porta, Lopez-de-Silanes, Shleifer, and Vishny, 1998), ethnicity and religion fractionalization (Alesina, Devleeschauwer, Easterly, Kurlat, and Wacziarg, 2003), and a landlocked indicator (one if landlocked; zero otherwise). The null hypothesis tested is "Instruments are redundant". We report robust test statistics estimated using Baum, Schaffer, and Stillman (2011), which are distributed according to a chi-squared distribution with degrees of freedom equal to the product of the number of endogenous regressors (1) and the numbers of IVs tested (the total number of observations is 291). The procedure begins with the four IVs listed below (Round 1) and is repeated successively until all redundant IVs are eliminated. The final list of IVs is determined in Round 2. In Panel B, we show the TSLS regression (second step) on the CARs in the local stock market index, in the period before (using CAR $[-10,-3]$ and CAR $[-5,-3]$ winsorized at the $1 \%$ level) sovereign debt downgrades [ratings FMR(First Mover using Ratings) sample]. IVs used for TI are common versus civil law, ethnic fractionalization and religion fractionalization. Coefficient is the regression coefficient. $z$ and $p$-value also reported are the robust $z$-value and $p$-value of the coefficient. The regression constant is not shown. UID is the under-identification test, which reports the Kleibergen-Paap rk LM statistic and associated chi-square $p$-value. OID is the over-identification test, which reports the Hansen $J$ statistic and associated chi-square $p$-value. WID is the weak-identification test reports both the Cragg-Donald Wald $F$-statistic and the Kleibergen-Paap rk Wald $F$ statistic. Also reported are the Stock-Yogo weak identification test critical values ( $10 \%$ maximal) for IV relative bias and size, respectively. $* * * * * *$, and * denote statistical significance (SS) at the $1 \%, 5 \%$, and $10 \%$ level, respectively.

Panel A: Instrument selection for TI index

\begin{tabular}{|c|c|c|c|c|c|c|c|c|}
\hline \multirow[b]{2}{*}{ Instrument } & \multicolumn{4}{|c|}{ Round 1} & \multicolumn{4}{|c|}{ Round 2} \\
\hline & & Test statistic & $p$-value & SS & & Test statistic & $p$-value & SS \\
\hline \multirow{4}{*}{\multicolumn{2}{|c|}{$\begin{array}{l}\text { Common versus civil law } \\
\text { Ethnicity fractionalization } \\
\text { Religion fractionalization } \\
\text { Landlocked }\end{array}$}} & 17.992 & 0.000 & $* * *$ & & 21.844 & 0.000 & $* * * *$ \\
\hline & & 63.342 & 0.000 & $* * * *$ & & 63.822 & 0.000 & $* * * *$ \\
\hline & & 12.294 & 0.001 & $* * * *$ & & 11.624 & 0.001 & $* * * *$ \\
\hline & & 6.100 & 0.014 & $* *$ & & & & \\
\hline \multirow[b]{2}{*}{ Institutional Quality } & \multicolumn{4}{|c|}{$\mathrm{CAR}[-10,-3]$} & \multicolumn{4}{|c|}{$\operatorname{CAR}[-5,-3]$} \\
\hline & Coefficient & $z$-value & $p$-value & SS & Coefficient & $z$-value & $p$-value & SS \\
\hline TI index & 0.007 & 2.450 & 0.014 & $* *$ & 0.006 & 3.540 & 0.000 & **** \\
\hline \multicolumn{9}{|l|}{ Test statistics } \\
\hline UID (Kleibergen-Paap rk LM statistic) & & 66.620 & 0.000 & $* * * *$ & & 66.620 & 0.000 & $* * * *$ \\
\hline OID (Hansen J-statistic) & & 1.173 & 0.556 & & & 1.872 & 0.392 & \\
\hline WID (Kleibergen-Paap rk Wald F-statistic) & & 61.139 & & & & 61.139 & & \\
\hline WID (Cragg-Donald Wald F-statistic) & & 40.094 & & & & 40.094 & & \\
\hline Stock-Yogo WID 10\% relative bias & & 9.080 & & & & 9.080 & & \\
\hline Stock-Yogo WID 10\% size & & 22.300 & & & & 22.300 & & \\
\hline
\end{tabular}

announcement and then by taking the opposite position after the public announcement. ${ }^{28}$ In the case of bad news, this pattern is referred to as "SELL on the RUMOR, BUY on the NEWS." Brunnermeier (2005) also shows that traders have incentives to trade more aggressively before the announcement, which could be costly in the short run, but can increase their overall profit upon reversing their position after the announcement. This trading behavior can lead to an overreaction before and a partial reversal after the public announcement, resulting in destabilizing effects around the announcement. This pattern is expected to be stronger when trading becomes so intense (perhaps an indication of informed trader aggressiveness) that rumors of the upcoming announcement make it into the news.

To test the role of rumors in our context, we re-run the event study separately for downgrades preceded by a rumor

\footnotetext{
${ }^{28}$ Hirshleifer, Subrahmanyam, and Titman (1994) also generate trade reversals, where risk-averse insider traders unwind part of their risky position as soon as their private information is revealed to other traders.
}

of the upcoming downgrade in the ten days before the official announcement ( $\mathrm{SDN}=1$ ) and downgrades not preceded by a rumor $(S D N=0)$. Fig. 8 shows the CAAR $[-10,+10]$ for the subsample of low institutional quality events with $S D N=1$ $(n=57)$ and $\mathrm{SDN}=0(n=92)$. In Table 4, Panel A reports the daily average abnormal stock returns and their statistical significance, and Panel B reports announcement period CAARs. The results appear to be consistent with the Brunnermeier (2005) empirical implications. While the negative pre-announcement abnormal return is statistically significant regardless of whether rumors of the upcoming downgrade are in the news, the post-announcement reversal is statistically detectible only when rumors make it into the news, implying an overreaction before and a subsequent correction after the announcement. ${ }^{29}$ The reactions in the two subsamples at the time of the announcement are also telling. The announcement in the no-rumor case $(\mathrm{SDN}=0)$ is

\footnotetext{
${ }^{29}$ CAAR $[+2,+5]=+1.67 \%$ and CAAR $[+2,+10]=+3.19 \%$, both statistically significant.
} 
Table 4

Abnormal returns [low Transparency International (TI) downgrades] conditional on sovereign downgrade news (SDN); rumors.

This table presents daily abnormal index returns around the announcement of sovereign debt rating downgrades [low TI ratings FMR (First Mover using Ratings) sample] conditional on SDN. The SDN variable is manually collected and takes the value of one if in the ten trading days before the downgrade announcement, there is at least one news item (rumor) referring directly to the forthcoming downgrade, and zero otherwise. Panel A shows daily average abnormal return AAR $(t)$ for all events on each day $t$, using a world market model. Panel B shows the cumulative average abnormal returns (CAAR) for the event windows specified. Results are shown separately for $\mathrm{SDN}=0(n=92)$ and $\mathrm{SDN}=1(n=57)$. The FMR sample comprises ratings changes for a sovereign not preceded by another change in rating by any CRA in the previous 20 trading days. Relative day is the trading day relative to the day 0 and $p$-values are based on the Kolari and Pynnonen (2010) approach. ***,**, and * denote statistical significance (SS) at the $1 \%, 5 \%$, and $10 \%$ level, respectively.

\begin{tabular}{|c|c|c|c|c|c|c|}
\hline \multicolumn{7}{|c|}{ Panel A: Average abnormal returns (AARs) } \\
\hline \multirow[b]{2}{*}{ Relative day } & \multicolumn{3}{|c|}{$\mathrm{SDN}=0$ (no rumors) } & \multicolumn{3}{|c|}{$\mathrm{SDN}=1$ (rumors) } \\
\hline & AAR (percent) & $p$-value & SS & AAR (percent) & $p$-value & SS \\
\hline-10 & -0.188 & 0.619 & & -0.260 & 0.352 & \\
\hline-9 & -0.003 & 0.861 & & 0.005 & 0.656 & \\
\hline-8 & -0.242 & 0.597 & & -0.583 & 0.202 & \\
\hline-7 & -0.351 & 0.076 & $*$ & -0.486 & 0.026 & $* * *$ \\
\hline-6 & -0.426 & 0.024 & $* *$ & -0.189 & 0.351 & \\
\hline-5 & -0.331 & 0.102 & & -0.262 & 0.197 & \\
\hline-4 & -0.514 & 0.009 & $* * *$ & -1.055 & 0.002 & $* * * *$ \\
\hline-3 & -0.525 & 0.085 & $*$ & -0.629 & 0.093 & * \\
\hline-2 & 0.023 & 0.549 & & 0.010 & 0.407 & \\
\hline-1 & -0.356 & 0.059 & $*$ & -0.062 & 0.968 & \\
\hline 0 & -0.551 & 0.047 & $* *$ & -0.549 & 0.076 & * \\
\hline 1 & -0.989 & 0.000 & $* * * *$ & 0.304 & 0.568 & \\
\hline 2 & 0.177 & 0.736 & & 0.347 & 0.304 & \\
\hline 3 & 0.579 & 0.192 & & 0.308 & 0.674 & \\
\hline 4 & 0.685 & 0.020 & $* *$ & 0.710 & 0.013 & $* *$ \\
\hline 5 & -0.201 & 0.210 & & 0.307 & 0.385 & \\
\hline 6 & -0.080 & 0.717 & & 0.508 & 0.019 & $* *$ \\
\hline 7 & 0.170 & 0.325 & & 0.494 & 0.469 & \\
\hline 8 & -0.013 & 0.861 & & 0.251 & 0.316 & \\
\hline 9 & -0.213 & 0.132 & & -0.031 & 0.818 & \\
\hline 10 & -0.584 & 0.004 & $* * * *$ & 0.297 & 0.393 & \\
\hline \multicolumn{7}{|c|}{ Panel B: Cumulative average abnormal returns (CAARs) } \\
\hline & \multicolumn{3}{|c|}{$\mathrm{SDN}=0$ (no rumors) } & \multicolumn{3}{|c|}{$\mathrm{SDN}=1$ (rumors) } \\
\hline Event window & CAAR (percent) & $p$-value & SS & CAAR (percent) & $p$-value & SS \\
\hline$(-10,-3)$ & -2.581 & 0.002 & $* * *$ & -3.459 & 0.000 & $* * * *$ \\
\hline$(-5,-3)$ & -1.370 & 0.003 & $* * * *$ & -1.946 & 0.001 & $* * * *$ \\
\hline$(0,+1)$ & -1.539 & 0.000 & $* * *$ & -0.244 & 0.549 & \\
\hline$(+2,+5)$ & 1.240 & 0.151 & & 1.672 & 0.010 & $* * * *$ \\
\hline$(+2,+10)$ & 0.521 & 0.897 & & 3.193 & 0.002 & $* * * *$ \\
\hline$(-5,+5)$ & -2.002 & 0.009 & $* * * *$ & -0.571 & 0.603 & \\
\hline$(-10,+10)$ & -3.932 & 0.001 & $* * * *$ & -0.563 & 0.669 & \\
\hline
\end{tabular}

accompanied by a negative stock market reaction, indicating that the announcement still contains a negative surprise (CAAR $[0,+1]$ of $-1.54 \%, p$-value $<0.01$ ), and the stock market reaction in the rumor case $(\mathrm{SDN}=1)$ is muted upon the announcement but still followed by a reversal (resonating the empirical findings in Bhattacharya, Daouk, Jorgenson, and Kehr, 2000). ${ }^{30}$

\footnotetext{
${ }^{30}$ For completeness, we test for statistically significant differences between CAARs of the two subsamples ( $\mathrm{SDN}=0$ and $\mathrm{SDN}=1)$ using $t$ tests. We find no statistical differences in market reactions in the preevent period; at the event, a $1.3 \%$ more negative market reaction when $\mathrm{SDN}=0(p$-value $<0.05)$; the $[+2,+10]$ reversal when $\mathrm{SDN}=1$ is larger
}

\subsection{Summary}

Section 5 provides robust evidence in support of the leakage hypothesis. The pre-event stock market reaction is stronger in countries with lower institutional quality, a finding that holds even after incorporating outlook changes, controlling for liquidity differences, volatility changes, alternative definitions of the market model, and

\section{(footnote continued)}

by $2.67 \%$ ( $p$-value $<0.05$ ); and the overall effect when $\mathrm{SDN}=0$ is more negative for $[-10,+10]$ by $3.37 \%(p$-value $<0.10)$. 


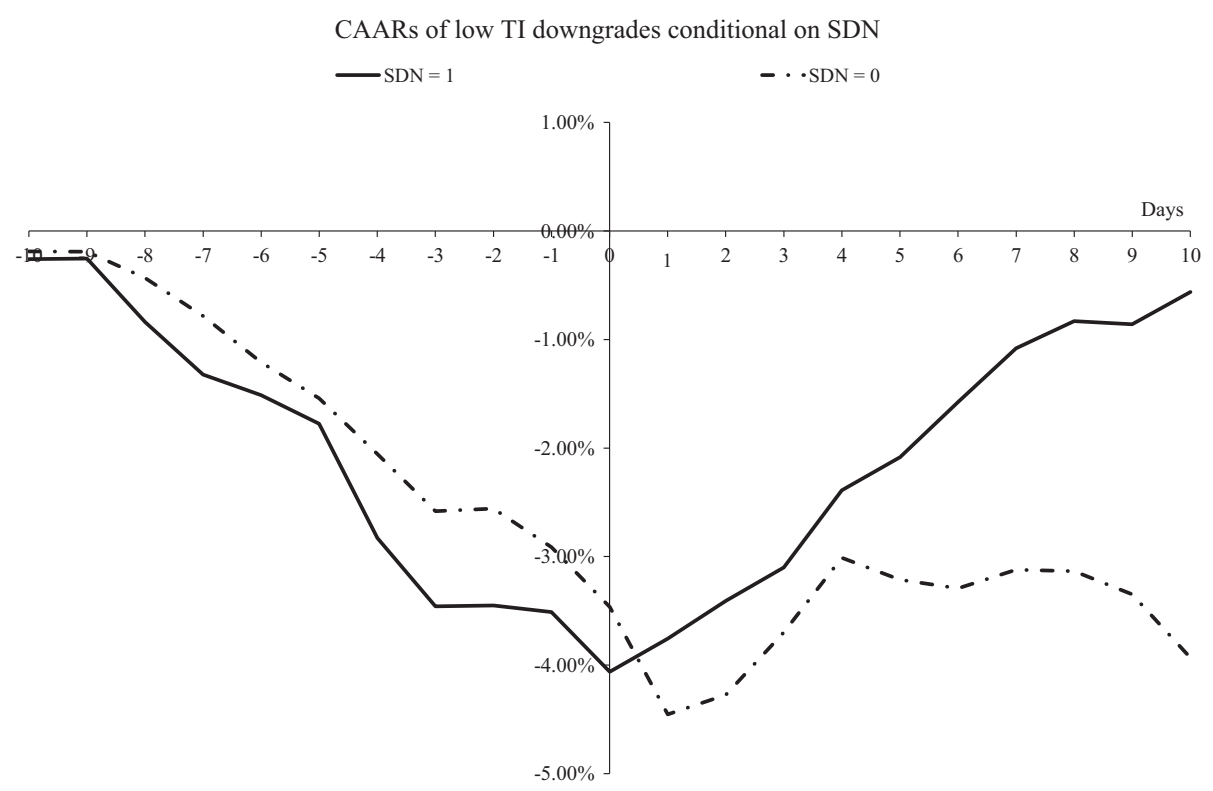

Fig. 8. Cumulative average abnormal returns (CAARs) for low Transparency International (TI) downgrades conditional on rumors. The graph shows the cumulative average abnormal returns for downgrades in sovereign ratings, for low institutional quality, by the amount of Sovereign Downgrade News (SDN). We proxy institutional quality using the TI Corruption Perception Index. SDN is assigned the value of one when there is at least one news item relevant to the downgrade before the announcement and zero otherwise. CAARs for the ratings FMR (First Mover using Ratings) sample (low TI downgrades) are shown separately for $\operatorname{SDN}=0(n=92)$ and $\operatorname{SDN}=1(n=57)$.

possible endogeneity bias. We also show evidence that the post-announcement reversal is consistent with an overreaction to downgrade rumors before the announcement.

\section{Can concurrent unrelated bad news explain the pre- announcement period negative abnormal returns?}

In this section, we test an alternative hypothesis for why stock markets decline before official sovereign downgrade announcements, namely, the presence of concurrent unrelated bad news in the pre-announcement window. To do so, we conduct event studies using the daily values of TRMI Buzz and TRMI Sentiment around sovereign downgrade announcements. If the pre-announcement period negative abnormal returns are driven by unrelated bad news instead of information leakage (i.e., rumors), we would expect to find an abnormal increase in Buzz or an abnormal decrease in Sentiment, or both, in the pre-event window, especially in the sample without rumors $(\mathrm{SDN}=0)$.

\subsection{Empirical results}

To measure abnormal changes in the news variables (TRMI Buzz and TRMI Sentiment), we estimate over the window $[-40,-11]$ and test over the window $[-10,+10]$. To estimate abnormal (log) Buzz, we subtract the average (log) Buzz over the estimation period from the daily (log) Buzz values in the testing period. ${ }^{31}$ To estimate abnormal

\footnotetext{
${ }^{31}$ Thomson Reuters recommends using observations that have a Buzz value (i.e. number of news items per day referring to the country of
}

Sentiment, we subtract the average sentiment in the estimation period from actual sentiment. Given that the TRMI variables begin in 1998, the total number of SDN $=0$ $(\mathrm{SDN}=1)$ events matched with available TRMIs after 1998 is 46 (36). For completeness and because of the change in sample size, we also repeat the main event studies for these two subsamples and report both average abnormal returns and CAARs in Table 5 (Panels $A$ and $B$, respectively). Standard errors and $p$-values are estimated following Kolari and Pynnonen (2010).

Two conclusions are drawn from the results in Table 5: (1) TRMI Buzz and TRMI Sentiment, as well as the SDN classification, are validated, and (2) evidence that concurrent unrelated bad news cannot explain the preannouncement period negative abnormal returns is obtained. Confirming the validity of the news-related variables, we find no abnormal Sentiment or Buzz before no-rumor downgrades $(\mathrm{SDN}=0)$, whereas we find negative abnormal sentiment before downgrades preceded by rumors $(\mathrm{SDN}=1)$. For example, in Panel $\mathrm{B}$, the Cumulative Average Abnormal Index (CAAI) for Sentiment in the window $[-5,-3]$ is negative with $p$-value $<0.01$ when $\mathrm{SDN}=1$. Both variables exhibit significant abnormal values at the announcement in both subsamples (i.e., $\mathrm{SDN}=0$

\footnotetext{
(footnote continued)

interest) greater than five hundred. This is because these news items are read by the TRMI proprietary algorithm to construct TRMI Sentiment. Hence, to improve accuracy of the Sentiment variable, TRMI recommends using observations with a daily Buzz value greater than five hundred. For more information about the TRMI Sentiment construction, see MarketPsych LLC's website: https://www.marketpsych.com.
} 
Table 5

Abnormal returns, Buzz and Sentiment [low Transparency International (TI) downgrades] conditional on rumors.

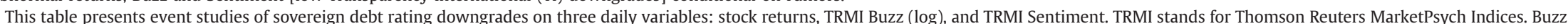

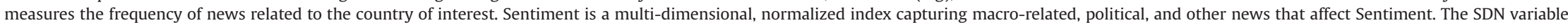

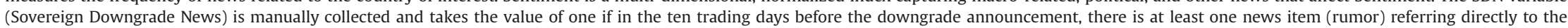

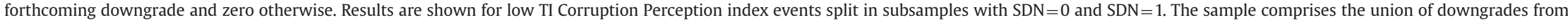

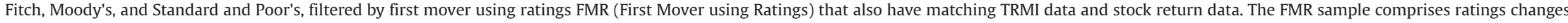

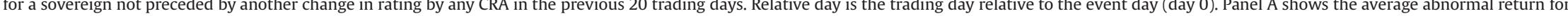

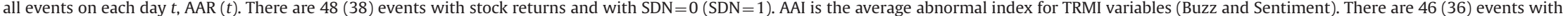

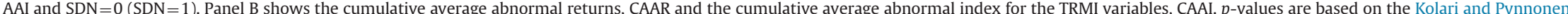
(2010) approach. ${ }^{* * * * * * *}$, and * denote statistical significance (SS) at the $1 \%, 5 \%$, and $10 \%$ level, respectively.

Panel A: Average abnormal returns (AAR) and average abnormal TRMIs (AAI)

$\mathrm{SDN}=0$ (no rumors)

$\mathrm{SDN}=1$ (rumors)

\begin{tabular}{|c|c|c|c|c|c|c|c|c|c|c|c|c|c|c|c|c|c|c|}
\hline \multirow[b]{3}{*}{ Relative day } & & \\
\hline & \multicolumn{3}{|c|}{ Stock returns } & \multicolumn{3}{|c|}{ TRMI Buzz } & \multicolumn{3}{|c|}{ TRMI Sentiment } & \multicolumn{3}{|c|}{ Stock returns } & \multicolumn{3}{|c|}{ TRMI Buzz } & \multicolumn{3}{|c|}{ TRMI Sentiment } \\
\hline & AAR (percent) & $p$-value & SS & AAI & $p$-value & SS & AAI & $p$-value & SS & AAR (percent) & $p$-value & SS & AAI & $p$-value & SS & AAI & $p$-value & SS \\
\hline-10 & -0.214 & 0.877 & & -0.008 & 0.842 & & 0.007 & 0.482 & & -0.578 & 0.144 & & 0.070 & 0.456 & & 0.019 & 0.427 & \\
\hline-9 & -0.113 & 0.744 & & 0.014 & 0.932 & & -0.006 & 0.446 & & -0.170 & 0.309 & & 0.061 & 0.728 & & -0.005 & 0.801 & \\
\hline-8 & -0.678 & 0.024 & $* *$ & -0.019 & 0.743 & & -0.007 & 0.624 & & -0.995 & 0.119 & & 0.005 & 0.929 & & -0.011 & 0.522 & \\
\hline-7 & -0.482 & 0.018 & $*$ & 0.050 & 0.459 & & -0.004 & 0.873 & & -0.024 & 0.717 & & 0.139 & 0.120 & & -0.008 & 0.524 & \\
\hline-6 & -0.436 & 0.012 & $* *$ & 0.035 & 0.759 & & 0.005 & 0.971 & & -0.377 & 0.202 & & 0.051 & 0.612 & & -0.016 & 0.255 & \\
\hline-5 & -0.341 & 0.181 & & 0.030 & 0.622 & & -0.006 & 0.478 & & -0.143 & 0.353 & & 0.244 & 0.130 & & -0.013 & 0.268 & \\
\hline-4 & -0.656 & 0.003 & $* *$ & 0.107 & 0.295 & & -0.005 & 0.528 & & -1.528 & 0.001 & $* * *$ & 0.186 & 0.489 & & -0.033 & 0.005 & $* * *$ \\
\hline-3 & -0.438 & 0.490 & & 0.135 & 0.184 & & 0.008 & 0.553 & & -1.016 & 0.049 & $* *$ & 0.309 & 0.056 & $*$ & -0.020 & 0.129 & \\
\hline-2 & 0.135 & 0.430 & & 0.179 & 0.201 & & -0.016 & 0.103 & & -0.204 & 0.863 & & 0.499 & 0.002 & $* * *$ & -0.027 & 0.116 & \\
\hline-1 & -0.326 & 0.326 & & 0.022 & 0.966 & & -0.009 & 0.193 & & -0.475 & 0.218 & & 0.711 & 0.000 & $* * *$ & -0.033 & 0.065 & * \\
\hline 0 & -0.514 & 0.057 & * & 0.313 & 0.026 & $* *$ & -0.033 & 0.003 & **** & -0.651 & 0.090 & $*$ & 0.866 & 0.000 & $* * *$ & -0.066 & 0.000 & $* * *$ \\
\hline 1 & -1.161 & 0.005 & $* * *$ & 0.300 & 0.038 & $* *$ & -0.041 & 0.000 & $* * *$ & 0.489 & 0.536 & & 0.925 & 0.000 & $* * *$ & -0.073 & 0.000 & $* * *$ \\
\hline 2 & 0.355 & 0.684 & & 0.203 & 0.090 & $*$ & -0.032 & 0.007 & $* * *$ & 0.283 & 0.787 & & 0.631 & 0.000 & $* * *$ & -0.028 & 0.030 & $* *$ \\
\hline 3 & 1.033 & 0.077 & * & 0.153 & 0.460 & & -0.037 & 0.000 & $* * * *$ & 0.397 & 0.634 & & 0.539 & 0.001 & $* * *$ & -0.018 & 0.360 & \\
\hline 4 & 1.091 & 0.015 & $* *$ & 0.038 & 0.748 & & -0.012 & 0.205 & & 1.062 & 0.011 & $* *$ & 0.533 & 0.001 & $* * *$ & 0.006 & 0.658 & \\
\hline 5 & -0.155 & 0.236 & & 0.140 & 0.236 & & -0.012 & 0.379 & & 0.442 & 0.349 & & 0.407 & 0.016 & $* *$ & 0.001 & 0.860 & \\
\hline 6 & 0.175 & 0.789 & & 0.169 & 0.197 & & -0.017 & 0.112 & & 0.586 & 0.009 & $* * *$ & 0.455 & 0.008 & $* * *$ & 0.005 & 0.588 & \\
\hline 7 & 0.557 & 0.053 & $*$ & 0.075 & 0.654 & & -0.015 & 0.149 & & 0.702 & 0.375 & & 0.373 & 0.025 & ** & -0.010 & 0.980 & \\
\hline 8 & 0.120 & 0.573 & & -0.015 & 0.950 & & -0.014 & 0.673 & & 0.385 & 0.176 & & 0.384 & 0.011 & $* *$ & -0.001 & 0.922 & \\
\hline 9 & 0.000 & 0.020 & $* *$ & -0.040 & 0.641 & & -0.018 & 0.426 & & -0.014 & 0.962 & & 0.305 & 0.056 & $*$ & -0.013 & 0.322 & \\
\hline 10 & -0.813 & 0.015 & $* *$ & -0.025 & 0.969 & & -0.024 & 0.161 & & 0.582 & 0.203 & & 0.293 & 0.094 & * & -0.010 & 0.678 & \\
\hline
\end{tabular}




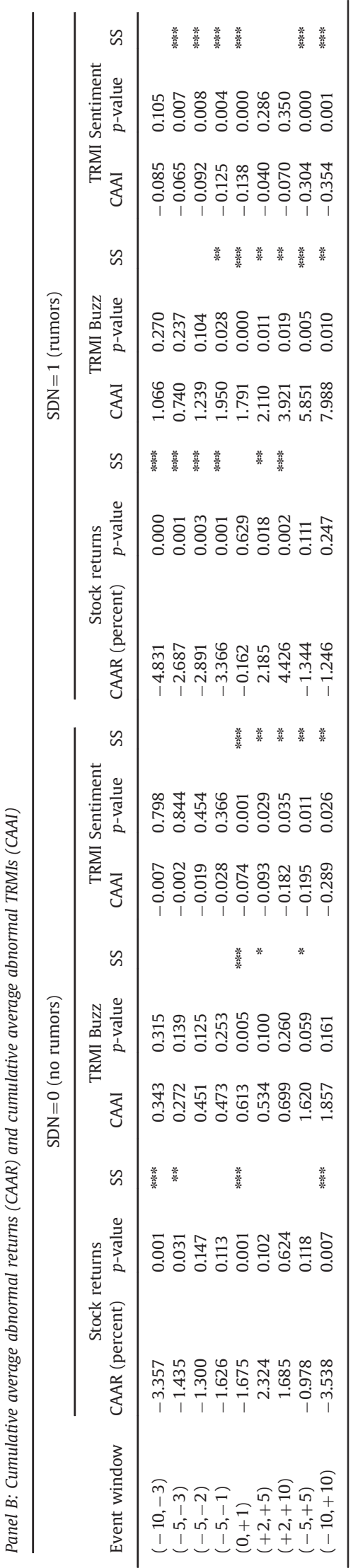

and $\mathrm{SDN}=1$ ), as expected. Table 5, Panel B, reports positive (negative) abnormal reactions for Buzz (Sentiment) over the $[0,+1]$ window $(p$-value $<0.01)$ for both subsamples. ${ }^{32}$

Beyond establishing the validity of the news-related variables, the results in Table 5 also show that the negative pre-announcement abnormal return persists both in the absence of rumors on the upcoming downgrade and in the absence of concurrent unrelated bad news, as shown by the insignificant abnormal Buzz and Sentiment in all preevent windows when $\mathrm{SDN}=0 .{ }^{33}$ We therefore conclude that concurrent unrelated bad news cannot explain our results. Interestingly, when $\mathrm{SDN}=1$, Sentiment is more affected than Buzz before the announcement, indicating that Sentiment is influenced more by rumors than unrelated news.

Buzz and Sentiment could be informative about spillovers from one country to another. For example, a downgrade in one country could be perceived as a signal about a potential downgrade in a neighboring country. Such a signal would likely generate discussion in the news and, hence, would be picked up by the TRMI variables. Gande and Parsley (2005) and Afonso, Furceri and Gomes (2012) find evidence for contagion in government bond yields across countries following sovereign debt downgrades. Focusing on sovereign yield responses to rating changes in EU countries, Afonso, Furceri and Gomes (2012) also offer evidence for bi-directional causality between yields and rating changes, consistent with event anticipation. Our results emphasize a large decline in the stock market before an official announcement in countries with weaker institutions, a finding that is hard to reconcile with the anticipation hypothesis operating in such countries. More importantly, we find that negative abnormal stock returns continue to arise in samples without any rumor related to the forthcoming downgrade or abnormal changes in the TRMI variables (i.e., without any news, related or unrelated) before the announcement that a spillover effect from a public downgrade of another country's sovereign debt would presumably generate, further suggesting the lack of an anticipation effect.

As a last robustness check, we re-run our tests separately for crisis (i.e., Asian, Russian, and eurodebt crises) and noncrisis periods. Our results are qualitatively unchanged.

\section{Policy implications}

Our results provide evidence of trading on leaked information in local stock markets, particularly in countries with lower institutional quality. This raises the question of where the potential information leakage could be coming from. The IOSCO Code of Conduct document (IOSCO, 2004) provides detailed guidelines as to the process CRAs should use to release their reports (see Section 2). In the EU, a 2009 regulation on CRAs (EU, 2009, p. 28) required that CRAs "inform the rated entity at

\footnotetext{
${ }^{32}$ The abnormal reaction of TRMIs on the announcement provides further validation evidence.

${ }^{33}$ Table 5, Panel A, does not report a single day with significant abnormal Buzz or Sentiment in the pre-event window when $\mathrm{SDN}=0$.
} 
least 12 hours before publication of the credit rating". In 2013, the so-called 12-hour rule was amended to a 24hour rule (EU, 2013; Annex I, Section D, Part I). Therefore, in many countries, when a CRA is preparing to announce a downgrade, a number of government officials see the rating report during the consultation process before its public release. As a result, any one of these government officials or individuals from the CRA could leak this information (intentionally or unintentionally) to local market participants, journalists, or politicians.

This interpretation is consistent with concerns EU policy makers express about potential leakage of information during the consultation process. For instance, the 2011 Roundtable on CRAs by the European Commission cites opposition to recommending that three days' notice be given for sovereign rating changes, "mainly because of market abuse risks." In addition, EU (2013) required that CRA announcements be scheduled, not unscheduled, events, to take place on three Fridays a year after markets close.

Renewed concerns about the breach of confidentiality during the consultation process were recently expressed by capital market regulators in Europe. On December 2, 2013, the European Securities and Markets Authority (ESMA) published results of a sovereign ratings investigation assessing the governance, conflicts of interest, resourcing adequacy, confidentiality controls, and timing of publication of rating actions (ESMA, 2013). With respect to confidentiality, Section 2.2 of the report states that ESMA “...is concerned that confidential information has been passed on to third parties who should not be privy to it". With respect to timeliness, Section 2.3 of the report states that ESMA "observed significant and frequent delays between the decision taken by the rating committee and the publication of sovereign ratings. In particular, there were instances of publication of ratings more than five days after the rating decision had been approved by the rating committee and, in at least one case even two weeks after the date of the committee."

Thus, while a consultation process is encouraged by IOSCO (2004) and the EU (2013) requires that such a process start at least 24 hours before the official announcement, an upper bound on the consultation window is not specified. As implied by ESMA (2013), a delay over five days is likely to be associated with the destabilizing effects of leakage that we show in this paper, or market abuse as noted by EC (2011). We therefore offer a few policy recommendations related to revisions of official sovereign rating (and outlook) announcements by CRAs.

The simplest solution could be to avoid the consultation process altogether in the several days before the current scheduled announcement, as markets can evaluate the information value inherent in upcoming CRA announcements. CRAs could still discuss information with rated entities for verification purposes, but such communication could end several weeks before the scheduled announcement date without CRAs having to reveal their intentions with respect to their rating decision (if possible). Should the consultation process immediately before the announcement remain, we propose that an upper bound be placed on the consultation window. At the moment, CRAs in the EU are required to give at least 24-hour notice to government officials before they publicly announce their decision to change a rating or outlook, but they can publish their decision days or even weeks after consulting with local government officials. We argue that the consultation process be constrained such that all communication between the CRA and government officials be completed, say, within 48 hours of the announcement, so that the probability of leakage is decreased through a shorter consultation window. Rating agencies could reserve the right to make unscheduled announcements, especially after unexpected events. Current EU legislation allows this, subject to appropriate explanations, but in that case it would probably be best to dispense with any consultation or limit it to 48 hours.

Finally, to prevent the destabilizing stock market effects shown in this paper, we propose that the process through which information is shared between CRAs and local government officials, as well as the timing of this process, be defined uniformly worldwide to safeguard the information confidentiality.

\section{Conclusion}

We find evidence consistent with information leakage taking place during the consultation process between CRAs and government officials of the rated sovereign. Specifically, local stock markets decline before the public announcement of a sovereign rating downgrade, resulting in a significant market reaction prior to the event. We also find a causal link between institutional quality and negative pre-announcement abnormal returns. Incorporating outlook changes and watchlist inclusions to control for potential anticipation effects does not alter our findings. Using manually collected news searches as well as recently developed news frequency and content variables (Thomson Reuters MarketPsych Indices), we further find that stock markets in low institutional quality countries experience negative abnormal stock returns in the absence of both news related to the forthcoming downgrade (i.e., rumors) and news not related to the downgrade (that is, unrelated bad news are not driving the results), which is consistent with unobserved leakages driving the results. Evidence of a post-event reversal only in the presence of downgrade rumors provides further support to the view that the negative pre-announcement abnormal returns are an overreaction to information leakage.

Overall, our results are consistent with recent investigations related to the destabilizing effects of official announcements of sovereign ratings in the US and EU, and they lend support to recent regulations in the EU that require CRAs to publish their decisions on pre-announced dates. Our results suggest, however, that capital market regulators also pay attention to how information is communicated between CRAs and local governments, particularly the consultation window between the decision to downgrade and the public announcement of the downgrade.

\section{Appendix. Econometrics (event study and standard error estimation)}

We use a world market model to calculate abnormal returns as follows. For every event, the following time 
series regression is estimated using daily data in the window $[-270,-21]$ :

$R_{i t}=a_{i}+b_{i} R_{W t}+e_{i t}$,

where $R_{i t}$ is observation $i$ 's MSCI index return and $R_{W t}$ is the MSCI World index return. We then calculate abnormal returns $(A R)$ from the residuals for $[-20,+20]$ :

$\mathrm{AR}_{i t}=R_{i t}-\hat{\alpha}_{i}-\hat{\beta}_{i} R_{W t}$.

Finally, we obtain cumulative abnormal returns for different subperiods $\left[t_{1}, t_{2}\right]$ by adding up the corresponding abnormal returns over the event window:

$\mathrm{CAR}_{i}\left[t_{1}, t_{2}\right]=\mathrm{AR}_{i t_{1}}+\cdots+\mathrm{AR}_{i t_{2}}$.

We use different estimators to test for the statistical significance of average abnormal returns and average CARs (and we do this separately for upgrades and downgrades). We first use the cross-sectional variation of abnormal returns in the event window under the assumption that $\mathrm{AR}_{i t}$ is independently and identically distributed following a normal distribution with mean zero (under the null) and variance $\sigma^{2}$. Using $s_{t}$ as an estimator for $\sigma(N=$ number of events), we define the test statistic based on the average abnormal return $\left(\mathrm{AAR}_{t}\right)$ :

$Z=\sqrt{N} \frac{\mathrm{AAR}_{t}}{s_{t}} \sim t_{N-1}$

$\mathrm{AAR}_{t}=\frac{1}{N} \sum_{i=1}^{N} \mathrm{AR}_{i t}$

and

$s_{t}=\sqrt{\frac{1}{N-1} \sum_{i=1}^{N}\left(\mathrm{AR}_{i t}-\mathrm{AAR}_{t}\right)^{2}}$.

Similarly, for the CARs we define the test statistic

$Z=\sqrt{N} \frac{\mathrm{CAAR}_{i}\left[t_{1}, t_{2}\right]}{s} \sim N(0,1)$,

where the cumulative average abnormal return is

$\operatorname{CAAR}\left[t_{1}, t_{2}\right]=\frac{1}{N} \sum_{i=1}^{N} \operatorname{CAR}_{i}\left[t_{1}, t_{2}\right]$

and the standard deviation is

$s=\sqrt{\frac{1}{N-1} \sum_{i=1}^{N}\left(\operatorname{CAR}_{i}\left[t_{1}, t_{2}\right]-\operatorname{CAAR}\left[t_{1}, t_{2}\right]\right)^{2}}$.

This test statistic accounts for event-induced variance as it uses an estimate of the cross-sectional variation of abnormal returns in the event window (testing period).

Boehmer, Musumeci, and Poulsen (1991) propose another way to account for event-induced variance based on standardized abnormal returns. Abnormal returns $\mathrm{AR}_{i}$ in the event window are standardized by the time series standard deviation of $\mathrm{AR}_{i t}$ in the estimation period
$[-270,-21]$. We define

$\overline{\mathrm{AR}}_{i}=\frac{1}{250} \sum_{t=1}^{250} \mathrm{AR}_{i t}$

and

$\bar{s}_{i}=\sqrt{\frac{1}{249} \sum_{t=1}^{250}\left(\mathrm{AR}_{i t}-\overline{\mathrm{AR}}_{i}\right)^{2} .}$

The standardized abnormal returns are then defined as

$\mathrm{SAR}_{i t}=\frac{\mathrm{AR}_{i t}}{\bar{S}_{i}}$

The Boehmer, Musumeci, and Poulsen (1991) t-test is constructed by dividing the average $\mathrm{SAR}_{i t}$ by their crosssectional standard deviation:

$T_{\mathrm{BMP}}=\sqrt{N} \frac{\mathrm{ASAR}_{t}}{S}$,

where

$\operatorname{ASAR}_{t}=\frac{1}{N} \sum_{i=1}^{N} \mathrm{SAR}_{i t}$

and

$S=\sqrt{\frac{1}{N-1} \sum_{i=1}^{N}\left(\mathrm{SAR}_{i t}-\mathrm{ASAR}_{t}\right)^{2} .}$

Kolari and Pynnonen (2010) extend Eq. (13) to also account for the cross-sectional correlation of abnormal returns. They do this because, in some cases, the correlation among abnormal returns (of different events) cannot be assumed to be zero. Hence, the independence assumption is violated. To address this concern they propose an adjustment to Eq. (13), which accounts for cross-correlation of residual returns in the estimation period. Letting $\bar{r}$ being the mean cross-correlation in the estimation period among residual returns, they propose the following test statistic:

$T_{\mathrm{KP}}=T_{\mathrm{BMP}} \sqrt{\frac{1-\bar{r}}{1+(N-1) \bar{r}}}$.

As a robustness check, we also use the more traditional method proposed by Brown and Warner (1980). This method estimates the standard deviation of average abnormal returns from the time series of average abnormal returns in the estimation period $[-270,-21]$ :

$\bar{s}=\sqrt{\frac{1}{249} \sum_{t=1}^{250}\left(\mathrm{AAR}_{t}-\overline{\mathrm{AAR}}\right)^{2}}$

where $\mathrm{AAR}_{t}$ is as defined in Eq. (5) and

$\overline{\mathrm{AAR}}=\frac{1}{250} \sum_{t=1}^{250} \mathrm{AAR}_{t}$.

The corresponding estimation of the standard deviation for the CAARs for window $\left[t_{1}, t_{2}\right]$ is given by

$s^{*}=\sqrt{\left(t_{2}-t_{1}+1\right)} \bar{s}$. 
We use the Kolari and Pynnonen (2010) specification as defined in Eq. (16) as our baseline case. Our results also hold using the standard errors of Brown and Warner (1980) and Boehmer, Musumeci, and Poulsen (1991).

\section{References}

Afonso, A., Furceri, D., Gomes, P., 2012. Sovereign credit ratings and financial markets linkages: application to European data. Journal of International Money and Finance 31, 606-638.

Alesina, A., Devleeschauwer, A., Easterly, W., Kurlat, S., Wacziarg, R., 2003. Fractionalization. Journal of Economic Growth 8, 155-194.

Baum, C.F., Schaffer, M.E., Stillman, S., 2011. IVREG29: Stata Module for Extended Instrumental Variables/2SLS and GMM Estimation (v9). Statistical Software Components, Boston College, Department of Economics, Boston, MA.

Beaver, W.H., Shakespeare, C., Soliman, M.T., 2006. Differential properties in the ratings of certified versus non-certified bond-rating agencies. Journal of Accounting and Economics 42, 303-334.

Bekaert, G., Harvey, C.R., Lundblad, C., 2007. Liquidity and expected returns: lessons from emerging markets. Review of Financial Studies 20, 1783-1831.

Berwart, E., Guidolin, M., Milidonis, A., 2014. An empirical analysis of changes in the relative timeliness of issuer-paid vs. investor-paid ratings. Social Science Research Network 〈http://papers.ssrn.com/ sol3/papers.cfm?abstract_id $=2439492\rangle$.

Bhattacharya, U., 2014. Insider trading controversies: a literature review. Annual Review of Financial Economics. (forthcoming).

Bhattacharya, U., Daouk, H., 2002. The world price of insider trading. Journal of Finance 57, 75-108.

Bhattacharya, U., Daouk, H., Jorgenson, B., Kehr, C.-H., 2000. When an event is not an event: the curious case of an emerging market. Journal of Financial Economics 55, 69-101.

Boehmer, E., Musumeci, J., Poulsen, A.B., 1991. Event-study methodology under conditions of event-induced variance. Journal of Financial Economics 30, 253-272.

Brooks, R., Faff, R.W., Hillier, D., Hillier, J., 2004. The national market impact of sovereign rating changes. Journal of Banking and Finance 28, 233-250.

Brown, S.J., Warner, J.B., 1980. Measuring security price performance. Journal of Financial Economics 8, 205-258.

Brunnermeier, M.K., 2005. Information leakage and market efficiency. Review of Financial Studies 18, 417-457.

CESR, 2004. CESR announces a call for evidence on credit rating agencies (Press release 04-385). Committee of European Securities Regulators, Paris, France.

Cheng, M., Neamtiu, M., 2009. An empirical analysis of changes in credit rating properties: timeliness, accuracy, and volatility. Journal of Accounting and Economics 47, 108-130.

Easterly, W., Levine, R., 2003. Tropics, germs, and crops: how endowments influence economic development. Journal of Monetary Economics 50, 3-39.

EC, 2011. Roundtable on credit rating agencies. European Commission, Directorate General Internal Market and Services, Brussels, Belgium.

ESMA, 2013. Credit rating agencies: sovereign ratings investigation. European Securities and Markets Authority, Paris, France.

EU, 2009. Regulation (EC) no. 1060/2009 of the European Parliament and of the Council. Official Journal of the European Union L302, 1-31.

EU, 2013. Regulation (EC) no. 462/2013 of the European Parliament and of the Council. Official Journal of the European Union L146, 1-33.

Gande, A., Parsley, D.C., 2005. News spillovers in the sovereign debt market. Journal of Financial Economics 75, 691-734.
Hill, P., Faff, R., 2010. The market impact of relative agency activity in the sovereign ratings market. Journal of Business Finance and Accounting 37, 1309-1347.

Hirshleifer, D., Subrahmanyam, A., Titman, S., 1994. Security analysis and trading patterns when some investors receive information before others. Journal of Finance 49, 1665-1698.

IOSCO, 2004. Code of conduct fundamentals for credit rating agencies. International Organization of Securities Commissions, Madrid, Spain.

IOSCO, 2008. Code of conduct fundamentals for credit rating agencies. International Organization of Securities Commissions, Madrid, Spain.

Kaminsky, G., Schmukler, S.L., 2002. Emerging market instability: do sovereign ratings affect country risk and stock returns? World Bank Economic Review 16, 171-195.

Khwaja, A.I., Mian, A., 2005. Unchecked intermediaries: price manipulation in an emerging stock market. Journal of Financial Economics 78, 203-241.

Kolari, J.W., Pynnonen, S., 2010. Event study testing with cross-sectional correlation of abnormal returns. Review of Financial Studies 23, 3996-4025.

Kothari, S., Warner, J., 2007. Econometrics of event studies. In: Eckbo, B.E. (Ed.), Handbook of Empirical Corporate Finance, Vol. 1. , ElsevierNorth-Holland, Amsterdam, pp. 3-36.

Kroft, S., 2012. Congress: trading stock on inside information? 〈http:// www.cbsnews.com/news/ congress-trading-stock-on-inside-information>.

La Porta, R., Lopez-de-Silanes, F., Shleifer, A., Vishny, R.W., 1998. Law and finance. Journal of Political Economy 106, 1113-1155.

Lesmond, D., Ogden, J., Trzcinka, C., 1999. A new estimate of transaction costs. Review of Financial Studies 12, 1113-1141.

Martell, R., 2005. The effect of sovereign credit rating changes on emerging stock markets. Social Science Research Network 〈http:// papers.ssrn.com/sol3/papers.cfm?abstract_id=686375 $\rangle$.

Milidonis, 2013. Compensation incentives of credit rating agencies and predictability of changes in bond ratings and financial strength ratings. Journal of Banking and Finance 37, 3716-3732.

Rossi, S., 2012. Italy extends rating agencies probe to Fitch. 〈http://www. reuters.com/article/2012/01/24/us-italy-fitchidUST $\rangle$.

S\&P's, 2013. Pre-publication notice to issuers. Standard \& Poor's Ratings Services, June 20.

SEC, 2003. Testimony concerning rating the rating agencies: the state of transparency and competition. Before the House Subcommittee on Capital Markets, Insurance, and Government Sponsored Enterprises, Committee on Financial Services, April 2

SEC, 2008. Summary report of issues identified in the commission staff's examinations of select credit rating agencies. US Government Printing Office, Washington, DC.

SEC, 2011. Summary report of commission staff's examinations of each nationally recognized statistical rating organization. US Government Printing Office, Washington, DC.

Staiger, D.O., Stock, J.H., 1997. Instrumental variables regression with weak instruments. Econometrica 65, 557-586.

Stambaugh, R.F., Yu, J., Yuan, Y., 2012. The short of it: investor sentiment and anomalies. Journal of Financial Economics 104, 288-302.

Stock, J., Yogo, M., 2005. Testing for weak instruments in linear IV regression. In: Andrews, D., Stock, J. (Eds.), Identification and Inference for Econometric Models: Essays in Honor of Thomas Rothenberg, Cambridge University Press, Cambridge, UK, pp. 80-108.

Tetlock, P.C., Saar-Tsechansky, M., Macskassy, S., 2008. More than words: quantifying language to measure firms' fundamentals. Journal of Finance 63, 1437-1467.

Wall Street Journal, 1998. World watch - Europe:Russia debt rating may be lowered. March 6 .

Wall Street Journal, 2011. US probes rating-cut trades: regulators subpoena hedge funds, others over actions ahead of S\&P downgrade. Eaglesham, J.. (September 20). 